\title{
Optimal Heat Pump Integration in Industrial Processes
}

\author{
Anna S. Wallerand*1 ${ }^{* 1}$ Maziar Kermani $^{1}$, Ivan Kantor ${ }^{1}$, and François Maréchal ${ }^{\dagger 1}$ \\ ${ }^{1}$ École Polytechnique Fédérale de Lausanne (EPFL) Valais Wallis, Switzerland
}

\begin{abstract}
Among the options for industrial waste heat recovery and reuse which are currently discussed, heat pumping receives far less attention than other technologies (e.g. organic rankine cycles). This, in particular, can be linked to a lack of comprehensive methods for optimal design of industrial heat pump and refrigeration systems, which must take into account technical insights, mathematical principles and state-of-the-art features. Such methods could serve in a twofold manner: (1) in providing a foundation for analysis of heat pump economic and energetic saving potentials in different industries, and further (2) in giving directions for experimentalists and equipment manufacturers to adapt and develop heat pump equipment to better fit the process needs.

This work presents a novel heat pump synthesis method embedded in a computational framework to provide a basis for such analysis. The superstructure-based approach is solved in a decomposition solution strategy based on mathematical programming. Heat pump features are incorporated in a comprehensive way while considering technical limitations and providing a set of solutions to allow expert-based decision making at the final stage.

Benchmarking is completed by applying the method on a set of literature cases which yields improved-cost solutions between 5 and 30\% compared to those reported previously. An extended version of one case is presented considering fluid selection, heat exchanger network (HEN) cost estimations, and technical constraints. The extended case highlights a trade-off between energy efficiency and system complexity expressed in number of compression stages, gas- and sub-cooling. This is especially evident when comparing the solutions with 3 and 5 compression stages causing an increase of the coefficient of performance (COP) from 2.9 to 3.1 at $3 \%$ increase in total annualized costs (TAC).
\end{abstract}

Keywords: industrial refrigeration; fluid selection; MINLP superstructure; multi-objective optimization; genetic algorithm; waste heat recovery and valorization;

\footnotetext{
*anna.wallerand@epfl.ch, anna.wallerand@gmail.com

${ }^{\dagger}$ francois.marechal@epfl.ch
}

This is a pre-print version of the paper. DOI:..... 


\section{Acronyms}

$\begin{array}{ll}\text { Capex } & \text { Annualized capital expenses } \\ \text { CEPCI } & \text { Chemical engineering's plant cost index } \\ \text { COP } & \text { Coefficient of performance } \\ \text { GWP } & \text { Global warming potential } \\ \text { HEN } & \text { Heat exchanger network } \\ \text { HFC } & \text { Hydrofluorocarbons } \\ \text { HPS } & \text { Heat pump superstructure } \\ \text { LNG } & \text { Liquid natural gas } \\ \text { LP } & \text { Linear programming } \\ \text { MILP } & \text { Mixed integer linear programming } \\ \text { MINLP } & \text { Mixed integer nonlinear programming } \\ \text { MIP } & \text { Mixed integer programming } \\ \text { MOGA } & \text { Multi-objective genetic algorithm } \\ \text { NLP } & \text { Nonlinear programming } \\ \text { Opex } & \text { Yearly operating expenses } \\ \text { ORC } & \text { Organic rankine cycle } \\ \text { PA } & \text { Pinch analysis } \\ \text { PI } & \text { Process integration } \\ \text { TAC } & \text { Total annualized costs } \\ \text { TSA } & \text { Total site analysis }\end{array}$




\section{Introduction}

Heat pumping has gained increasing attention during the past decades not only for household applications but also for improving energy efficiency of industrial processes through waste heat recovery and valorization at elevated temperatures $[1,2]$. As demonstrated in Appendix A.1 (Figure 11), research in the field of industrial waste heat recovery is largely dominated by organic rankine cycle (ORC) applications and thermoelectric devices. This may stem from a fully explored state-of-the-art of industrial heat pumps and integration methods; however, the marginal penetration of industrial heat pump systems (apart from basic refrigeration and airconditioning) $[2,3]$ contradicts this notion. The main barriers for broad usage in industry were identified as lack of knowledge and of comprehensive heat pump integration methods to provide improvement potentials $[2,3]$. This work mainly covers single fluid, mechanically driven systems due to their advanced technological development and operative flexibility (see Appendix A.1 for more explanation). After a state-of-the-art analysis of current synthesis methods, this work presents a novel heat pump superstructure with a bi-level solution strategy in the methodology section, followed by application of the method to various literature cases in the results and discussion section.

\section{State-of-the-art}

The focus of this work lies on mechanically driven heat pump synthesis methods for industrial processes. Since these techniques rely on modeling state-of-the-art heat pump technologies, a short review of available heat pump features was conducted. Chua et al. [2] and most recently Arpagaus et al. [4] presented comprehensive literature reviews on advances in mechanically driven (multi-temperature) heat pump systems. The most recurring features relevant for large-scale modeling of industrial heat pumps were identified and are presented in Table 1. These include multi-stage compression and expansion, ejectors, cascaded cycles, gas-cooling, subcooling, economizers, and presaturators. Other developments, which impose different system architectures (desiccant cooling [2]) or more refined equipment modeling (scroll and oil-free compressors $[2,4-6])$ are not discussed in this work.

Table 2 provides an overview of the studies introducing synthesis methods discussed in this section. In the presented approaches, it is differentiated between conceptual methods which are based on expert judgment, heuristic rules, or graphical analysis; and mathematical methods, which rely of mathematical programming to perform systematic optimization. This work presents a contribution to the latter which is thus discussed at greater length.

\subsection{Conceptual methods}

Conceptual, or insight-based, methods are not limited by the problem size and therefore always lead to a solution though global optimality will seldom be reached. As early as 1974, Barnés and King [7] and later Cheng and Mah [8] proposed methods based on a set of heuristic rules, dynamic programming, and expert judgment for synthesis of industrial heat pump systems. In 1978, a milestone was achieved, when Linnhoff and Flower [9] proposed a method now commonly known as pinch analysis (PA) [10] which, for the first time, allowed systematic analysis of a process net thermodynamic requirements and maximum heat recovery potential. This led Townsend and Linnhoff [11] to derive the theoretical foundation for ideal placement of heat engines and heat pumps based on the principles of PA. They concluded that system 
Table 1: Heat pump features considered in this work as identified by $[2,4]$.

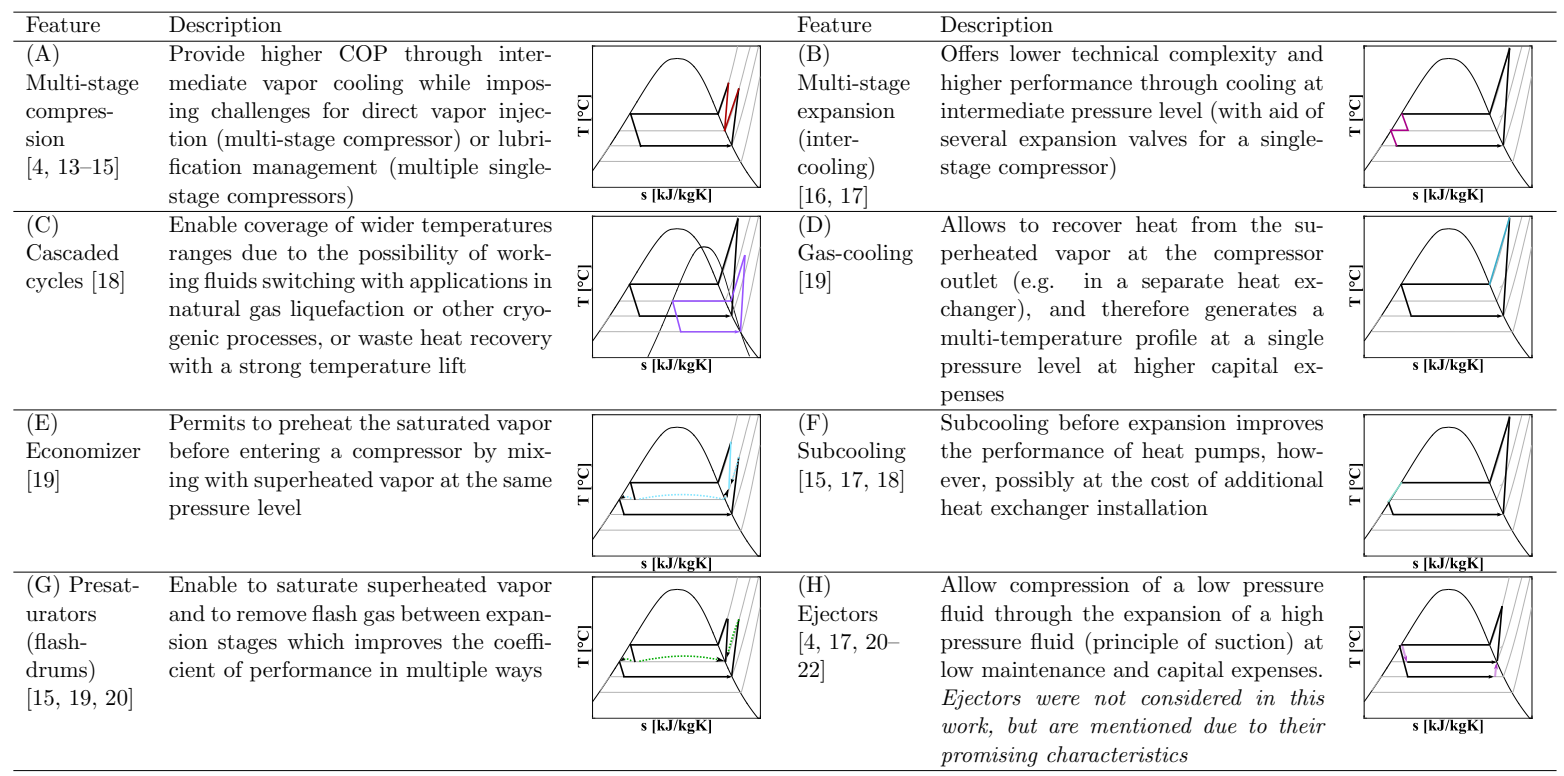

improvement from a thermodynamic standpoint can only be achieved if heat pumps are placed across the process pinch temperature (A.1). Industrial capital budgeting, however, is seldom based upon thermodynamic objectives. Other drivers play a major role including economic and environmental concerns as well as technical constraints. Therefore, subsequent researchers added thermo-economic principles and technical constraints into their decision process as shown e.g. by Ranade [12] with a trade-off formula between the temperature lift and heat exchanger cost in total site analysis (TSA) (see Table 2).

\subsection{Mathematical methods}

Mathematical methods ensure identification of an ideal point with regard the selected objective(s); however, convergence of optimization techniques becomes increasingly difficult with growing problem size. Therefore, many studies considered a reduced solution space, such as discretized temperature levels, simplified heat pump cycles, disregarding PA principles, or preselecting working fluids. The studies presenting mathematical methods are analyzed in the following paragraphs based on selected characteristics.

Temperature level selection In the literature, temperature level (used here interchangeably with pressure level) selection was handled in two ways. The primary approach relies on predefined or discretized temperature levels among which compressor units are activated using integer variables. The first comprehensive methodology for optimal industrial heat pump design based on discrete temperature levels was presented by Shelton and Grossmann [23][24] in the form of a mixed integer linear programming (MILP) superstructure. Many subsequent authors used discretized temperature levels (as depicted in Table 2), resulting in a diminished solution space and therefore increasing the risk of identifying a sub-optimal solution. Fewer authors presented methods with continuous temperature levels as part of the decision variables, which renders the problem structure nonlinear as presented e.g. by Colmenares and Seider [25].

Pinch analysis The principles of PA were considered in most methodologies listed in Table 2. Few authors presented algorithms neglecting PA, which reduced the problem size at the cost of disregarding the heat recovery system and its dependencies. 
Heat pump features In modeling heat pump features, three approaches addressing different levels of detail were observed in the literature. In the first group (1), heat pump performance was modeled based on general thermodynamic principles. It aids in estimating potentials for improvements reachable with heat pump integration but lacks specification of real fluids or system design. Works contained in the second group (2) modeled basic single-stage heat pump cycles based on real fluids assuming that superposition of simple cycles could represent more complex systems. This leads to underestimation of performance and thus sub-optimal solutions could be generated. The third group (3) contains work presenting rigorous heat pump models including technical features from Table 1. Most of these included multi-stage compression and pre-saturation, while some additionally considered liquid sub-cooling, preheating before compression, or gas-cooling, and very few authors examined multi-stage expansion including Aspelund et al. [26]. No previous work has comprehensively included all identified heat pump features.

Objective function Apart from the work of Becker et al. [27], the works discussed here have presented mathematical approaches for single-objective optimization of industrial heat pump systems with objectives such as minimizing exergy losses or total cost. In praxis, decisionmaking is based on many factors and it is thus difficult to obtain the global solution from single-objective optimization. Therefore, it is advantageous to derive multiple solutions such that the final decision can be based on several criteria including expert judgment, which could be facilitated by multi-objective optimization.

Fluid selection Fluid selection has not been considered extensively in heat pumping literature. Some authors have compared different working fluids based on thermodynamic principles, such as Oluleye et al. [28], while others mainly derive the optimal mass flow rates or composition from preselected fluids, including Kamalinejad et al. [29]. Few researchers have integrated fluid selection into the optimization in the form of integer, binary, or continuous variables such as Becker [27], Vaidyaraman and Maranas [30], or Colmenares and Seider [31]. The candidate fluids were principally selected based on fluid critical properties and triple point.

\subsection{Discussion and goal}

The discussion of studies presenting conceptual and mathematical methods for optimal heat pump design and integration with industrial processes is summarized as follows.

1. Conceptual methods provide important insight to problems but cannot assess solution optimality. The advantage is, however, that technical infeasibilities and practical constraints can be considered without facing computational problems.

2. Mathematical methods may experience convergence issues for large scale problems due to increasing complexity. Therefore, many studies considered a reduced solution space.

3. Few studies provide a combination of conceptual and mathematical approaches, which can harvest the advantages of both methods, e.g. through introduction of technical constraints, or multi-solution generation.

4. The potential impact of heat pumping for industrial waste heat recovery is not clearly communicated.

This paper addresses the gaps denoted (2) and (3) by presenting a novel comprehensive superstructure synthesis method which is solved using mathematical programming for optimal integration of industrial heat pump systems. Preliminary versions of this heat pump superstructure (HPS) [32, 33] were generalized and extended to incorporate fluid selection, HEN 
Table 2: Literature summary of synthesis methods for heat pump design and integration with industrial processes.

\begin{tabular}{|c|c|c|c|c|c|c|c|c|c|c|c|c|c|c|c|c|c|c|c|}
\hline \multirow[t]{2}{*}{ Authors } & \multirow[t]{2}{*}{ Year } & \multirow[t]{2}{*}{ Focus } & \multicolumn{2}{|c|}{ Method } & \multirow[t]{2}{*}{$\mathrm{PA}$} & \multirow{2}{*}{$\begin{array}{l}\text { Property } \\
\text { calc. }\end{array}$} & \multirow{2}{*}{$\begin{array}{l}\text { Temp. } \\
\text { discret. }\end{array}$} & \multirow[t]{2}{*}{ Detail } & \multirow[t]{2}{*}{ Objective } & \multicolumn{7}{|c|}{ Cycle features } & \multicolumn{3}{|c|}{ Fluid } \\
\hline & & & Conc. & Math. & & & & & & (A) & (B) & (C) & (D) & $(\mathrm{E})$ & (F) & (G) & & Selecti & \\
\hline Current work & & HP & $\mathrm{TC}$ & MINLP & $\checkmark$ & $\mathrm{CP}$ & $0.5 \mathrm{~K}$ & 3 & opex, capex & $\checkmark$ & $\checkmark$ & $\checkmark$ & $\checkmark$ & $\checkmark$ & $\checkmark$ & $\checkmark$ & $\mathrm{S}$ & $\checkmark$ & Integers \\
\hline Zhang et al. [34] & 2016 & AHP & & MINLP & & - & contin. & 1 & TAC & & & $\checkmark$ & & & & & G & & \\
\hline Oluleye et al. [35] & 2016 & $\mathrm{HP} / \mathrm{AHP} / \mathrm{HE} / \mathrm{AHT}$ & TP & & $\checkmark$ & HYSYS & $10 \mathrm{~K}$ & 2 & Fuel & & & $\checkmark$ & & & & & $\mathrm{s}$ & & TP \\
\hline Oluleye et al. [36] & 2016 & $\mathrm{HP} / \mathrm{AHP} / \mathrm{HE} / \mathrm{AHT}$ & & MILP & $\checkmark$ & HYSYS & $10 \mathrm{~K}$ & 2 & TAC & & & 2 & & & & & $\mathrm{~s}$ & & Binary \\
\hline Dinh et al. [37] & 2015 & HP & & MILP & $\checkmark$ & PR & fixed & 3 & Power & $\checkmark$ & & $\checkmark$ & & & $\checkmark$ & $\checkmark$ & $\mathrm{s}$ & $(\checkmark)$ & Flowrates \\
\hline Kamalinejad et al. [29] & 2015 & HP & & MINLP & $\checkmark$ & $\mathrm{RP}$ & contin. & 3 & $\mathrm{TAC}$ & $\checkmark$ & & $\checkmark$ & $\checkmark$ & $\checkmark$ & $\checkmark$ & $\checkmark$ & $\mathrm{S}$ & $(\checkmark)$ & Flowrates \\
\hline Liu et al. [38] & 2014 & HP & ТP & & $\checkmark$ & - & fixed & 3 & Power & $\checkmark$ & $\checkmark$ & $\checkmark$ & & & & & $\mathrm{S}$ & $\checkmark$ & TP \\
\hline Khan and Lee [39] & 2013 & HР & & NLP & $\checkmark$ & $\mathrm{PR}$ & contin. & 3 & Power & $4^{(*)}$ & & & & & & & M & $(\checkmark)$ & Composition \\
\hline Hackl and Harvey [40] & 2013 & HP & TP & & $\checkmark$ & simple & fixed & 1 & - & & & $\checkmark$ & & & & & $\mathrm{G}$ & & \\
\hline Becker [27],[41] & 2012 & HP & & MINLP & $\checkmark$ & Belsim & contin. & 2 & opex,capex & & & $\checkmark$ & $\checkmark$ & & $\checkmark$ & & $\mathrm{s}$ & $\checkmark$ & Binary \\
\hline Zhang and Xu [42] & 2011 & HP & $\mathrm{TC}$ & MINLP & $\checkmark$ & & fixed & 3 & Exergy & $\checkmark$ & & $\checkmark$ & $\checkmark$ & $\checkmark$ & $\checkmark$ & $\checkmark$ & $\mathrm{s}$ & $(\checkmark)$ & Flowrates \\
\hline Hasan et al. [43] & 2009 & HP & & MINLP & & simple & contin. & 3 & Power & $\checkmark$ & & $\checkmark$ & & & & $\checkmark$ & $\mathrm{S} / \mathrm{M}$ & $(\checkmark)$ & Flowrates \\
\hline Nogal et al. [44] & 2008 & HP & & MINLP & $\checkmark$ & HYSYS & contin. & 3 & capex/Power & $\checkmark$ & $\checkmark$ & $\checkmark$ & & & & $\checkmark$ & M & $(\checkmark)$ & Composition \\
\hline Aspelund et al. [26] & 2007 & HP & TP & & & HYSYS, SRK & fixed & 3 & Exergy & 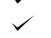 & $\checkmark$ & 2 & & & & $\checkmark$ & $\mathrm{s}$ & 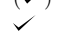 & TP \\
\hline Bagajewicz and Barbaro [45] & 2003 & HP & & NLP & $\checkmark$ & simple & contin. & 1 & opex & & & $\checkmark$ & & & & & G & & \\
\hline Holiastos and Manousiouthakis [46] & 2002 & $\mathrm{HE} / \mathrm{HP}$ & & LP & $\checkmark$ & simple & fixed & 1 & $\mathrm{TAC}$ & & & $\checkmark$ & & & & & G & & \\
\hline Vaidyaraman and Maranas [47] & 2002 & HP & & NLP & $\checkmark$ & SRK & contin. & 3 & Power & & $\checkmark$ & $\checkmark$ & & & & $\checkmark$ & M & $(\checkmark)$ & Composition \\
\hline Maréchal and Kalitventzeff [48] & 2001 & HP & $\mathrm{TC}$ & MILP & $\checkmark$ & Belsim & fixed & 3 & Exergy & $\checkmark$ & & $\checkmark$ & & & & $\checkmark$ & $\mathrm{s}$ & $\checkmark$ & Binary \\
\hline Vaidyaraman and Maranas [30] & 1999 & HP & & MILP & $\checkmark$ & [49] & $1-8 \mathrm{~K}$ & 3 & TAC & $\checkmark$ & & $\checkmark$ & & $\checkmark$ & & $\checkmark$ & $\mathrm{s}$ & $\checkmark$ & Binary \\
\hline Kauf [50] & 1999 & $\mathrm{HP}$ & TP & & 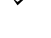 & {$[49]$} & 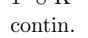 & 2 & $\mathrm{COP}$ & & & 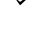 & & 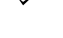 & & 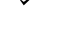 & $\begin{array}{l}\mathrm{s} \\
\mathrm{S}\end{array}$ & & \\
\hline Wallin and Berntsson [51] & 1993 & $\mathrm{HP} / \mathrm{AHP} / \mathrm{AHT}$ & TEP & & $\checkmark$ & generic & fixed & 1 & TAC & & & & & & & & G & & \\
\hline Linnhoff and Dhole [52] & 1992 & HP & $\mathrm{TP}$ & & 2 & simple & fixed & 3 & Power & $\checkmark$ & & $\checkmark$ & & & & $\checkmark$ & $\mathrm{s}$ & & \\
\hline Swaney [53] & 1989 & $\mathrm{HE} / \mathrm{HP}$ & & LP & $\checkmark$ & simple & fixed & 3 & TAC & $\checkmark$ & & $\checkmark$ & & & & $\checkmark$ & $\mathrm{S}$ & & \\
\hline Colmenares and Seider $[25]$ & 1989 & $\mathrm{HE} / \mathrm{HP}$ & & NLP & $\checkmark$ & $\mathrm{PR}$ & contin. & 2 & TAC & & & $\checkmark$ & & & & & $\mathrm{s}$ & $\checkmark$ & Flowrates \\
\hline $\begin{array}{l}\text { Ranade }[12] \\
\text { R }]\end{array}$ & 1988 & & EP & & 2 & simple & contin. & 1 & TAC & & & 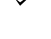 & & & & & G & & Howlates \\
\hline Colmenares and Seider [31] & 1987 & $\mathrm{HE} / \mathrm{HP}$ & & NLP & $\checkmark$ & $\mathrm{PR}$ & fixed & 2 & TAC & & & $\checkmark$ & & & & & $\mathrm{s}$ & $\checkmark$ & Flowrates \\
\hline Shelton and Grossmann [23] & 1986 & $\mathrm{HP}$ & & LP & $\checkmark$ & {$[54]$} & $1 \mathrm{~K}$ & 3 & TAC & $\checkmark$ & & $\checkmark$ & & & & $\checkmark$ & $\mathrm{s}$ & & \\
\hline Shelton and Grossmann [24] & 1986 & HP & & MILP & $\checkmark$ & {$[54]$} & $10 \mathrm{~K}$ & 3 & TAC & $\checkmark$ & & $\checkmark$ & & & & $\checkmark$ & $\mathrm{S}$ & & \\
\hline Townsend and Linnhoff [11] & 1983 & $\mathrm{HE} / \mathrm{HP}$ & ТP & & $\checkmark$ & Tabl. & fixed & 2 & Exergy & & & & & & & & $\mathrm{S}$ & & \\
\hline Cheng and Mah $[8]$ & 1980 & HP & $\mathrm{HR}$ & & & SRK & contin. & 3 & TAC & $\checkmark$ & & $\checkmark$ & $\checkmark$ & $\checkmark$ & $\checkmark$ & $\checkmark$ & $\mathrm{S}$ & $\checkmark$ & TP \\
\hline Barnés and King [7] & 1974 & HP & $\mathrm{HR}$ & MIP & & SRK & contin. & 3 & $\mathrm{TAC}$ & $\checkmark$ & & $\checkmark$ & $\checkmark$ & $\checkmark$ & $\checkmark$ & $\checkmark$ & $\mathrm{S}$ & & \\
\hline
\end{tabular}

(*) Fixed four stages in optimization study

pumps, HE - heat engines, AHP - absorption heat pumps, AHT - absorption heat transformers

Conceptual methods: TP - Thermodynamic principles, TC - Technical constraints, EP - Economic principles, HR - Heuristic rules, TEP - Thermo-economic principles;

PA: pinch analysis [10, 55] - CoolProp [56], RP - Refprop [57], SRK - Soave-Redlich-Kwong [58] equation of state, HYSYS - Aspen HYSYS software [59], simple - simplified estimations, PR - Peng-Robinson

Detail: Level of detail in modeling: 1 - general modeling based on thermodynamic estimations for a generic fluid, 2 - modeling of simplified (single-stage) cycles for specific fluids, 3 - full detail modeling of (multi-stage) heat pumps with advanced features for different fluids

Cycle features: (A) Multi-stage compression, (B) multi-stage expansion, (C) cascaded cycles, (D) gas cooling, (E) Economizer (preheating before compression), (F) sub-cooling, (G) presaturator

Fluid: T (types): S - single component fluid, M - fluit mixture, G - generic fluid; Selection: TP: thermodynamic principles 
cost estimation, technical constraints and a comprehensive list of heat pump features. A multiobjective decomposition solution strategy allows convergence for large problems and provides multiple solutions for expert judgment adapted to the diverse criteria relevant in industry. This strategy addresses the shortcomings of previous work and provides a clear design method based on a comprehensive superstructure and mathematical programming.

\section{Methodology}

\subsection{Problem statement}

Given an industrial process with thermal and material demands and a set of candidate utility technologies, including potential heat pumps, the goal is to find the optimal utility system including the optimal design of the heat pump system. The optimal heat pump layout should encompass specification of technologies, features, working fluid and operating conditions. This method, therefore, aims at providing a utility target and preliminary design of the heat pump system as the basis for detailed design considering dynamic behavior in a subsequent step.

\subsection{Superstructure synthesis}

A flowsheet and a temperature entropy diagram of the novel heat pump superstructure (HPS) are depicted in Figure 1. It illustrates the various potential pathways and features considered in the superstructure. Some features are represented in sample cycles.

The superstructure is equipped with a condenser and evaporator at the highest and lowest pressure levels, respectively. The intermediate levels additionally contain a presaturator, a post-compression gas-cooler, a subcooling heat exchanger, and a superheater. Compressors and valves are made available between all pressure levels. Superheated vapor exiting the compressor can be de-superheated in a heat exchanger (gas-cooler) and condensed (represented by one heat exchanger), and/or sent to a presaturator which saturates the fluid and separates it into its phases. Two-phase flow leaving the expansion valves can be evaporated (and potentially superheated by mixing or heat exchange) and then compressed or mixed with condensate with options of inter-cooling and/or subcooling before expansion.

\subsection{Mathematical formulation}

The statement above corresponds to a non-convex Mixed Integer Nonlinear Programming (MINLP) problem. The integer variables relate to activation of different technology options while nonlinearities mainly arise from capital cost correlations and the intrinsic nonlinearity of thermodynamic property correlations. Therefore, a decomposition strategy [62] is applied as presented in Figure 2 which incorporates the nonlinearities at the master level solving the linear problem at the slave level. The variables present in the nonlinear constraints are set at the master level and thus act as parameters for the slave optimization. At the slave level, the linear problem is solved and the decision variables contained in the linear constraints and the linear objective function are transferred to a post-computational analysis where the nonlinear capital cost correlations and objectives are calculated. Based on the objective function values, a convergence check is performed and a new iteration is initiated at the master level.

The main assumptions considered in the heat pump superstructure are:

- the thermodynamic behavior is at steady-state

- heat losses and pressure drops in piping and the components are negligible

- the outlet of a condenser is either saturated or subcooled 
- the outlet of an evaporator is either saturated or superheated

- isenthalpic expansion in the valves

- the minimum approach temperature difference is fixed for every stream (and follows the indications from the literature cases)

The conventions in the equations presented below are that scalar decision variables are represented by italic letters, scalar parameters by roman text, vectors are always represented in bold (italic for variables, roman for parameters), and sets are represented in roman bold uppercase.

\subsubsection{Master level}

At the master level, a black box optimization is performed where the variables present in the nonlinear constraints are the decision variables. These are mainly the heat pump saturation temperature levels $\left(T_{i}\right)$, the fluid $(d)$, the subcooling, gas cooling, and compressor preheating temperature differences $\left(\Delta T_{i, S C}, \Delta T_{i, D S H}, \Delta T_{i, P R E}\right)$, and all thermodynamic properties derived from these. An additional variable is introduced in order to vary the weight $(\xi)$ of the two components in the objective function at the slave level (see section 3.3.2 - objective function). The properties are retrieved from the open-source database CoolProp [56]. The variables and objective functions at the master level are found in Table 3. Black-box multi-objective nonlinear optimization is performed by Dakota [64] using a multi-objective genetic algorithm (MOGA) [65] which allows analysis of a wide solution space. The specifications used are presented in appendix A.2.

Objective function Different objective functions are of interest when optimizing industrial heat pumps such as the exergy efficiency, coefficient of performance (COP), environmental impact, or cost. Based on the literature cases considered in the results and discussion section, the objectives of the multi-objective optimization were based on economic criteria, i.e. annualized capital expenses (capex) and yearly operating expenses (opex) as shown in Equation 1.
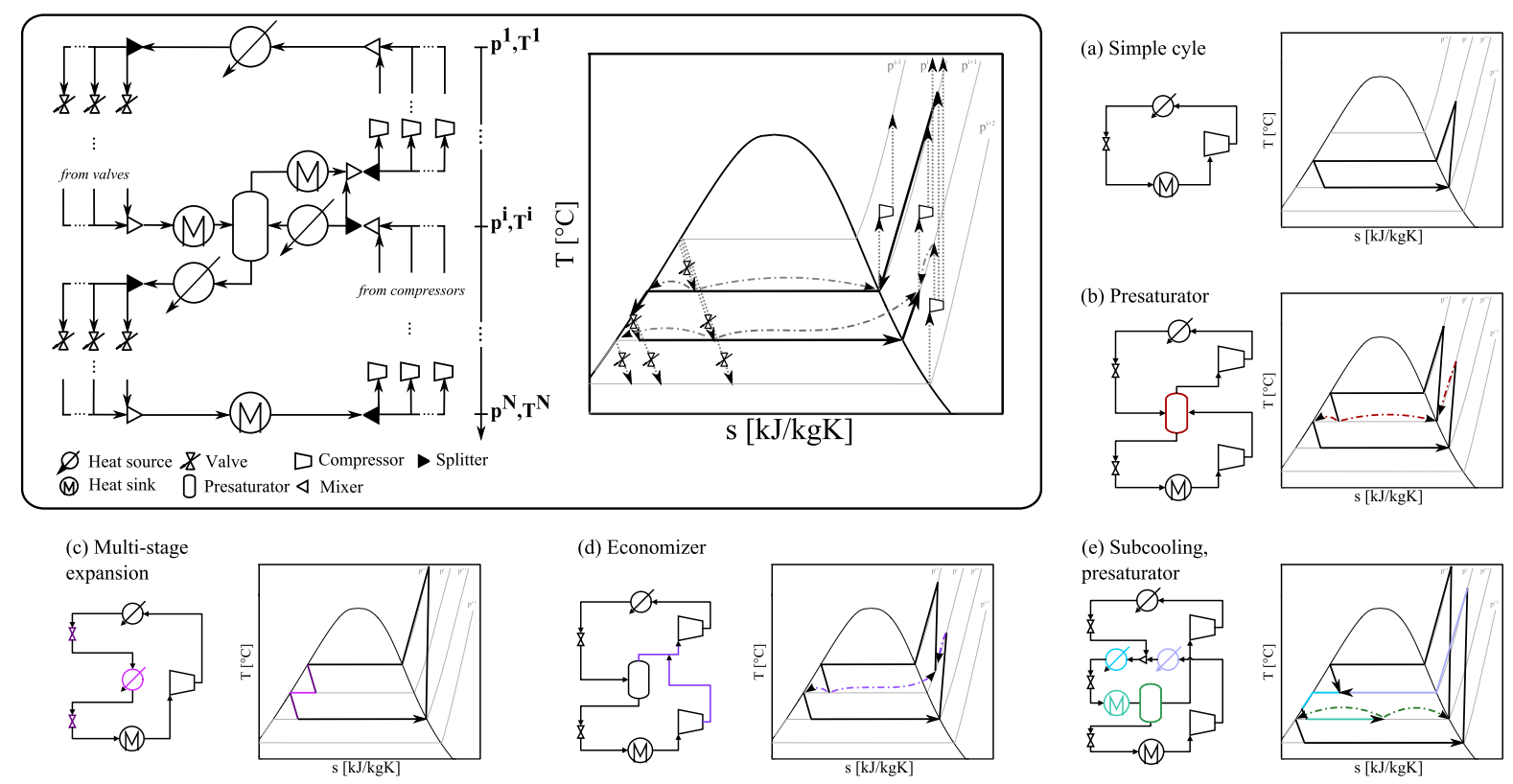

Figure 1: Flowsheet and temperature-entropy diagram of the HPS with sample cycles. 


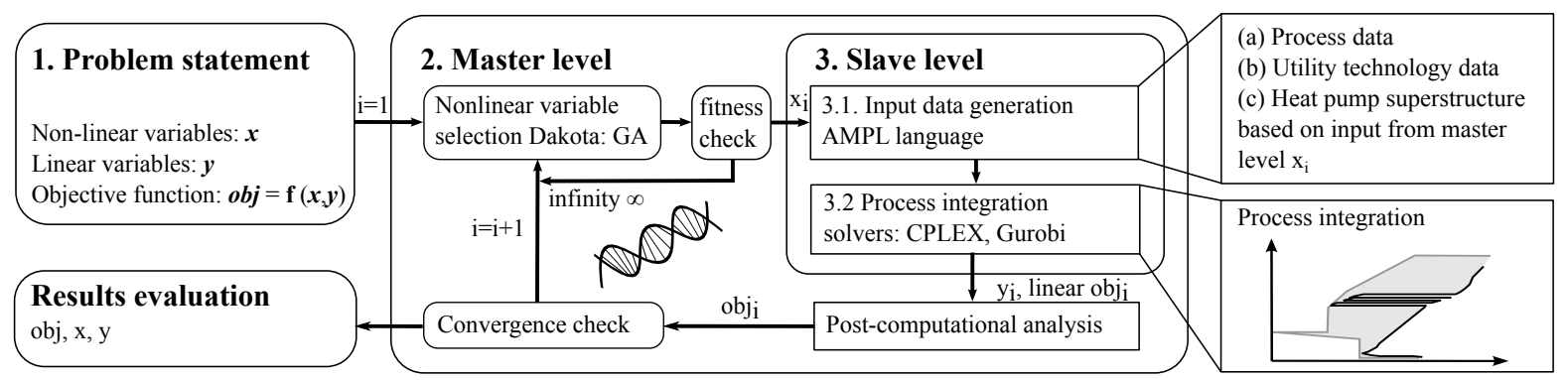

Figure 2: Flowchart of decomposition strategy solving MINLP superstructure implemented in Lua OSMOSE platform $[62,63]$.

$$
\min _{T_{i}, \Delta T_{i, D S H}, \Delta T_{i, S C}, \Delta T_{i, P R E}, d, \xi}\left\{C^{\text {opex }}, C^{\text {capex }}\right\}
$$

The capex (depicted in Equation 4) consists of the investment costs of all technologies $w$ and the HEN cost estimation calculated using Equation 3. The HEN area is estimated as suggested by Townsend and Linnhoff $[10,66]$ based on vertical intervals in the composite curves. HEN design based on mathematical principles, as well as optimization of the minimum approach temperature $\left(\Delta \mathrm{T}_{\min }\right)$ was not performed in this work, but could be added to the solution strategy.

Link to slave level The utility and heat pump technology sizing is performed at the slave level. The results from the slave optimization serve as input to calculate the master level objective functions. These are the maximum size $\left(f^{w}\right)$ and existence $\left(y^{w}\right)$ of each technology $w$ influencing the equipment investment and heat exchanger network cost estimation.

\subsubsection{Slave level}

The HPS is embedded in the utility targeting problem of Maréchal and Kalitventzeff [68] where the optimal utility system for an industrial process is found based on the thermal and material needs considering maximum heat recovery. This means that all elements of the heat pump, namely condensers, evaporators, compressors, presaturators (flash-drums) and gas-coolers, are present as utility technologies in the targeting approach. The main variables at the slave level are the size and existence of each utility technology, including all heat pump elements. The size of each technology is decided by optimization based on the objective function while remaining subject to physical and thermodynamic laws. To ensure mass and energy conservation within the heat pump, additional constraints are added at all saturated liquid, vapor, and superheated vapor points. Since the saturation temperature and respective pressure levels as well as the subcooling and superheated properties are set at the master level, component sizing is linearly dependent on the state properties. Therefore, the problem can be described as a multi-period Mixed Integer Linear Programming (MILP) problem which is solved using commercial software (AMPL modeling language [69]) with CPLEX [70]. Table 4 depicts the objective function and variables at the slave level. The utility targeting constraints are described in further detail in appendix C.1. The heat pump parameters for utility targeting as well as mass and energy balances are found in appendix C.2.

Objective function The MILP problem is solved with commercial solvers based on branch and cut methods for a single objective function. Investigation of a wide solution space regarding both objectives from the master level leaves two options for consideration. 
Table 3: Variables and objective function at master level.

\begin{tabular}{|c|c|c|c|c|}
\hline Description & Symbols & \multicolumn{3}{|c|}{ Equation } \\
\hline \multicolumn{5}{|l|}{ Objectives } \\
\hline $\begin{array}{l}\text { Yearly operating } \\
\text { penses (opex) }[\$ / y]\end{array}$ & $C^{\text {opex }}$ & \multicolumn{3}{|c|}{ from slave level, see Table 4} \\
\hline \multirow[t]{2}{*}{$\begin{array}{l}\text { Total investment cost } \\
{[\$]}\end{array}$} & $C^{I N V}$ & & $\sum_{w \in \mathbf{W}} C^{w}\left(f^{w}, y^{w}\right)+C^{H E N}$ & $(2)$ \\
\hline & & $\begin{array}{l}\mathbf{W} \\
f^{w} \\
y^{w} \\
C^{w}\end{array}$ & $\begin{array}{l}\text { set of utility technologies } w \\
\text { maximum size of technology } w \\
\text { existence of technology } w \\
\text { investment cost function of technology } w \text {, see appendix C.2 }\end{array}$ & \\
\hline \multirow[t]{3}{*}{$\begin{array}{l}\text { Heat exchanger network } \\
\text { cost }\left(^{*}\right)[\$]\end{array}$} & $C^{H E N}$ & & $\max _{p}\left\{\left[\mathrm{c}_{1}+\mathrm{c}_{2} \cdot\left(\frac{A_{t o t, p}^{H E N}}{N_{m i n, p}^{H E N}}\right)^{\mathrm{c}_{3}}\right] \cdot N_{m i n, p}^{H E N}\right\}$ & (3) \\
\hline & & & $A_{t o t, p}^{H E N}=\sum_{k \in \mathbf{K}} \frac{1}{\Delta T_{\log , k}} \cdot\left[\sum_{c \in \mathbf{C}} \frac{\dot{Q}_{p, k}^{c}}{\alpha^{c}}+\sum_{h \in \mathbf{H}} \frac{\dot{Q}_{p, k}^{h}}{\alpha^{h}}\right](*)$ & \\
\hline & & $\begin{array}{l}\mathbf{K} \\
\mathbf{H}, \mathbf{C} \\
\Delta T_{\log , k} \\
\dot{Q}_{p, c}^{h, c} \\
\alpha_{p, k}^{c}, \alpha^{c} \\
A_{t o n}^{H E N} \\
N_{m i n, p}^{H+E} \\
\mathrm{c}_{1} \\
\mathrm{c}_{2} \\
\mathrm{c}_{3}\end{array}$ & $\begin{array}{l}\text { set of temperature intervals }\left\{1,2,3, \ldots, \mathrm{n}_{\mathrm{n}}\right\} \\
\text { set of hot, cold process and utility streams } \\
\text { set of cold process and utility streams } \\
{[\mathrm{K}] \text { logarithmic mean temperature difference }} \\
f_{p}^{h, c} \cdot \mathrm{Q}^{h, c}[\mathrm{~kW}] \text { contribution of hot } h \text {, cold stream } c \text { to temperature interval } k \text { in period } p \\
{\left[\mathrm{~kW} / \mathrm{m}^{2} \mathrm{~K}\right] \text { hot, cold stream } h, c \text { heat transfer coefficient }} \\
{\left[\mathrm{m}^{2}\right] \text { total heat exchanger network area }} \\
{[-] \text { minimum number of heat exchanger units }} \\
{[\$] \text { fixed cost parameter }} \\
{\left[\$ / \mathrm{m}^{2}\right] \text { scaling cost parameter }} \\
{[-] \text { non-linear parameter }}\end{array}$ & \\
\hline \multirow{2}{*}{$\begin{array}{l}\text { Annualized capital ex- } \\
\text { penses (capex) }[\$ / y]\end{array}$} & $C^{\text {capex }}$ & & $C^{I N V} \cdot(\tau+\mathrm{m})$ & $(4)$ \\
\hline & & & $\begin{array}{l}{[-] \frac{i \cdot(1+1)^{n}}{\left.(1+)^{n}\right)^{-1}} \text { investment cost annualization factor }} \\
{[-] \text { maintenance cost as fraction of total investment }}\end{array}$ & \\
\hline $\begin{array}{l}\text { Total annualized costs } \\
(\mathrm{TAC})[\$ / \mathrm{y}]\end{array}$ & $C^{T A C}$ & & $C^{\text {capex }}+C^{\text {opex }}$ & (5) \\
\hline \multicolumn{5}{|l|}{ Variables } \\
\hline Temperature levels & $T_{i}$ & {$\left[T_{i}^{\min }\right.$,} & $\left.\mathrm{T}_{i}^{\max }\right],[\mathrm{K}]$ saturation temperature levels & \\
\hline Subcooling & $\Delta T_{i, S C}$ & {$\left[0, \mathrm{~T}_{i, \mathrm{~S}}^{\mathrm{ma}}\right.$} & Cic $],[\mathrm{K}]$ temperature difference between condensate and subcooling outlet & \\
\hline De-superheating & $\Delta T_{i, D S H}$ & {$\left[0, \mathrm{~T}_{i, \mathrm{D}}^{\mathrm{ma}}\right.$} & SSH $],[\mathrm{K}]$ temperature difference in gas-cooling heat exchanger & \\
\hline Pre-heating & $\Delta T_{i, P R E}$ & {$\left[0, \mathrm{~T}_{i, \mathrm{P}}^{\mathrm{ma}}\right.$} & $\left.\begin{array}{l}\mathrm{Ax} \\
\mathrm{RE}\end{array}\right],[\mathrm{K}]$ temperature difference for preheating before compression & \\
\hline Fluid index & $d$ & $\{1,2, .$. & .., $\left.\mathrm{n}_{\mathrm{d}}\right\}$ from set of fluids $\mathbf{F}$ & \\
\hline Weighting factor & $\xi$ & {$[0,1],[-$} & {$[-]$ for objective function of slave optimization } & \\
\hline
\end{tabular}

(a) Constraining one objective with a variable controlled from the master level and minimizing the second objective or

(b) Defining a weighted sum of the two objectives $\left(w C^{T A C}\right)$ where the weighting factor $(\xi)$ is controlled at the master level.

Since alternative (a) generates more infeasible solutions and therefore leads to longer solution times, option (b) was selected and is expressed in Equation 6.

$$
\min _{f_{p}^{w}, f^{w}, y_{p}^{w}, y^{w}}\left\{w C^{T A C}\right\}
$$

Heat cascade The MILP slave model is subject to heat cascade constraints [68] which ensure heat transfer feasibility for maximum heat recovery. The set of equations are provided in appendix C.1 (Equation 13 - Equation 14).

Mass and energy balances All material and non-thermal energy requirements are described by a set of constraints. These equality constraints ensure that material/energy consumption 
and conversion are balanced within the system boundaries or compensated with help of the grid (utilities) which factors into the operating cost.

Variables The variables present at the slave level are the existence $\left(y_{p}^{w}\right)$ and sizing $\left(f_{p}^{w}\right)$ of each of the utility technologies $w$ during each period $p$ and the maximum size considering the entire operating range. Based on the objective function and thermodynamic input parameters selected at the master level, optimal sizes and operating conditions of all utilities including the heat pump technologies are derived within the optimization.

Heat pump specific constraints The general heat pump parameters such as the reference heat load of the evaporator and condenser and the reference electricity consumption of the compressors are presented in appendix C.2.1. These enter into the targeting constraints and are sized based on the process thermal requirements minimizing the objective function. Enforcing energy and mass conservation within the HPS requires additional constraints to be introduced. These are illustrated in further detail in appendix C.2.2. Mass and energy conservation are introduced at three different points on each pressure level, namely: the superheated vapor point after compression, the de-superheated or saturated vapor point before compression or condensation, and the saturated or subcooled liquid point after condensation or before evaporation. Since these points are fixed at the master level, all equations can be formulated with purely linear dependencies. Mass balances at all three points ensure that the working fluid mass flow rate is conserved throughout the heat pump system. Energy balance equations ensure that mixing (e.g. of two compressor outlets at the same pressure level) do not violate the energy conservation law. Superheated vapor mass and energy balances are introduced to study the effect of sensible heat recovery from the vapor (gas-cooling). This can either be achieved by installation of a separate heat exchanger (gas-cooler) or by accounting for sensible heat release in the condenser unit. Both options are separately modeled in this superstructure but does not have a major impact on the heat exchanger network cost estimation (since gas cooling in both cases imposes higher investment). The de-superheating temperature difference $\left(\Delta T_{D S H, i}\right)$ selected at the master level can be understood as the temperature from which sensible heat release is considered. This temperature difference does not influence the energy balance but by manipulating the inlet temperature of the de-superheating, HEN solutions which require stream splitting can be avoided, which has an influence on the heat cascade. If it is set to zero, gas-cooling is neglected and the sensible heat contained in the superheated vapor is considered as if it was available only at saturation temperature levels.

Apart from energy and mass conservation, technical constraints can be considered as introduced below.

Number of heat pump stages The maximum number of stages of a heat pump cycle consisting of one fluid can be restricted as shown in Equation 7.

$$
\sum_{i=2}^{n_{1}} \sum_{j=1}^{i-1} y^{g, \text { comp } i \rightarrow j} \leq \mathrm{n}_{g}^{\max } \quad \forall g \in \mathbf{G}
$$

Where

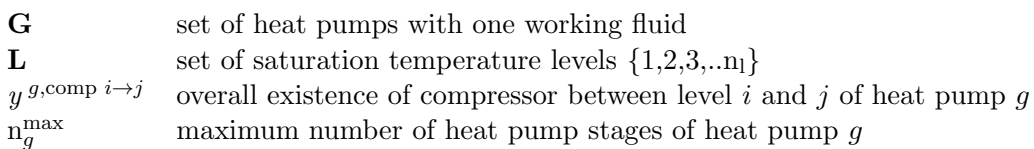


Compression ratio and minimum pressure Compressors with compression ratios or with pressure levels outside the bounds cannot be activated as depicted in Equation 8 .

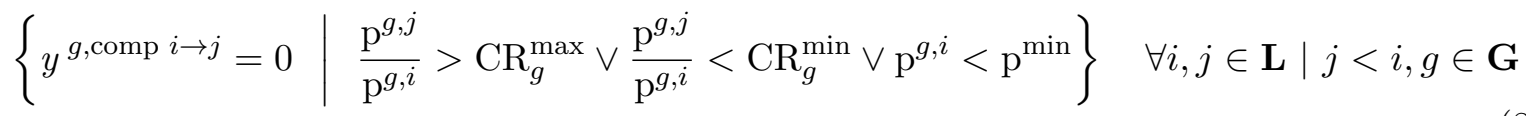

Where

$$
\begin{array}{ll}
\mathrm{p}^{g, k} & \text { [bar] saturation pressure level of heat pump } g \text { at saturation temperature level } k \\
\mathrm{CR}_{g}^{\min , \max } & \text { [bar/bar] minimum, maximum accepted compression ratio of heat pump } g \\
\mathrm{p}^{\text {min }} & \text { [bar] minimum accepted saturation pressure level }
\end{array}
$$

Heat exchanger size A minimum size for heat exchangers is introduced in the form of a soft constraint. Thereby, a fixed penalty cost is added to the units containing thermal streams as shown in Equation 9.

$$
\begin{aligned}
& \mathrm{C}^{\mathrm{fix}}=\mathrm{a} \cdot\left(\frac{\mathrm{Q}^{\text {min }}}{\mathrm{U} \cdot \mathrm{A} \cdot \Delta \mathrm{T}}\right)^{\mathrm{b}} \quad \forall h \in \mathbf{H}^{g}, g \in \mathbf{G} \\
& \mathrm{IV}_{1}^{h}=\mathrm{C}^{\mathrm{fix}}
\end{aligned}
$$

Where

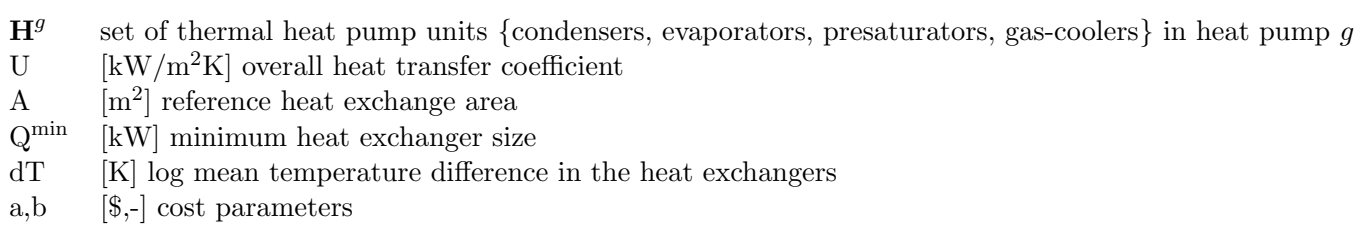

\subsection{Fluid selection}

Presuming fluid selection from known fluids and sub-critical operation, there are two options for conducting a fluid selection in the underlying method.

(a) the list of candidate fluids is added to the slave level, in which every unit (condenser, evaporator, compressors, etc.) is reproduced as many times as there are fluids; the fluids are then activated using binary variables connected to the existence of each unit $\left(y^{w}\right)$, or

(b) an integer variable referencing the fluid is added to the master level

The advantage of selection at the slave level, (a), is that cascaded cycles with different fluids can be designed and convergence of the decomposition strategy is reached after fewer iterations (due to fewer variables at the master level). The disadvantage is that the slave problem size increases proportionally with the number of fluids which impacts the MILP resolution time significantly. Both options were applied in this study depending on the respective problem statement (which will be indicated).

\section{Results and discussion}

This section is divided into three parts. In the benchmarking analysis, three case studies presenting optimal heat pump designs for industrial processes from the literature were selected. The literature results were reproduced with the heat pump superstructure (HPS) to validate its flexibility. During the optimization study, the multi-objective bi-level approach presented in the methodology is applied to the three literature cases, and compared to the previous solutions from the literature. In an extended analysis, one literature case is expanded to consider fluid 
Table 4: Variables and objective function at slave level.

\begin{tabular}{|c|c|c|c|c|}
\hline Description & Symbols & \multicolumn{3}{|c|}{ Equation } \\
\hline \multicolumn{5}{|l|}{ Objectives } \\
\hline \multirow[t]{2}{*}{$\begin{array}{l}\text { Weighted total annual- } \\
\text { ized costs }(\mathrm{TAC})[\$ / \mathrm{y}]\end{array}$} & $w C^{T A C}$ & & $\xi \cdot C^{\text {capex }}+(1-\xi) \cdot C^{\text {opex }}$ & $(10)$ \\
\hline & & $\xi$ & weighting parameter controlled from master level & \\
\hline $\begin{array}{l}\text { Yearly operating ex- } \\
\text { penses (opex) }[\$ / y]\end{array}$ & $C^{\text {opex }}$ & & $\sum_{p \in \mathbf{P}}\left(\sum_{w \in \mathbf{W}} \mathrm{OP}_{1, p}^{w} \cdot y_{p}^{w}+\mathrm{OP}_{2, p}^{w} \cdot f_{p}^{w}\right) \cdot \Delta \mathrm{t}_{p} \cdot \mathrm{occ}_{p}$ & $(11)$ \\
\hline \multirow[t]{2}{*}{ Sizing constraint } & & & $\mathrm{f}^{w, \min } \cdot y_{p}^{w} \leq f_{p}^{w} \leq \mathrm{f}^{w, \max } \cdot y_{p}^{w} \quad \forall p \in \mathbf{P}, w \in \mathbf{W}$ & \\
\hline & & $\begin{array}{l}\mathbf{P} \\
\mathbf{W} \\
f_{p}^{w} \\
y_{p}^{w} \\
\mathrm{OP}_{1, p}^{w} \\
\mathrm{OP}_{2, p}^{w} \\
\Delta \mathrm{t}_{p}^{w} \\
\mathrm{occ}_{p}\end{array}$ & $\begin{array}{l}\text { set of time periods }\left\{1,2,3, \ldots, \mathrm{n}_{\mathrm{p}}\right\} \\
\text { set of utility technologies } \\
\text { continuous variable for sizing technology } w \text { during period } p \\
\text { binary variable related to existence of technology } w \text { during } p \\
{[\$ / \mathrm{h}] \text { fixed operating cost in period } p} \\
{[\$ / \mathrm{h}] \text { proportional operating cost in period } p} \\
{[\mathrm{~h}] \text { operating time of period } p} \\
{[1 / \mathrm{y}] \text { occurrence of period } p}\end{array}$ & \\
\hline \multirow[t]{2}{*}{$\begin{array}{l}\text { Annualized capital ex- } \\
\text { penses (capex) }[\$ / y]\end{array}$} & $C^{\text {capex }}$ & & $\sum_{w \in \mathbf{W}} \mathrm{IV}_{1}^{w} \cdot y^{w}+\mathrm{IV}_{2}^{w} \cdot f^{w}$ & $(12)$ \\
\hline & & $\begin{array}{l}f^{w} \\
y^{w} \\
\mathrm{IV}_{1}^{w} \\
\mathrm{IV}_{2}^{w}\end{array}$ & $\begin{array}{l}\text { maximum size of technology } w \\
\text { overall existence of technology } w \\
{[\$ / y] \text { fixed cost related to the annualized, linearized investment of technology } w} \\
{[\$ / y] \text { proportional cost related to the annualized, linearized investment of technology }} \\
w\end{array}$ & \\
\hline \multicolumn{5}{|l|}{ Variables } \\
\hline Multiplication factor & $f_{p}^{w}$ & \multicolumn{3}{|c|}{$\left[\mathrm{f}^{w, \max }, \mathrm{f}^{w, \min }\right],[-]$ sizing factor of technology $w$ during period $p$} \\
\hline Use factor & $y_{p}^{w}$ & $\multicolumn{3}{|c|}{0,1},[-]$ existence of technology $w$ in period $p$ \\
\hline $\begin{array}{l}\text { Maximum multiplica- } \\
\text { tion factor }\end{array}$ & $f^{w}$ & \multicolumn{3}{|c|}{$\geq f_{p}^{w} \forall p \in \mathbf{P}$ maximum size of technology $w$} \\
\hline Overall use factor & $y^{w}$ & \multicolumn{3}{|c|}{$\geq y_{p}^{w} \forall p \in \mathbf{P}$ overall existence of technology $w$} \\
\hline
\end{tabular}

selection, technical boundary conditions, and HEN cost estimations better representing the reality of industrial problems.

\subsection{Benchmarking analysis}

The selection of the benchmark cases was based on their recurrence in the literature, even though not many cases were treated repeatedly, and diversity in their characteristics. Suitable cases could not be identified in the most recent literature due to insufficient data provision in terms of process stream data, cost functions, or detailed heat pump configurations. The selected cases were each treated in several publications.

(a) Case E2 was selected because it was treated in two consecutive studies by Shelton and Grossmann [23, 24] and due to its heating and cooling requirements which span over a continuous temperature range as shown in Figure 3(a). This case provides exploration potential of a multi-temperature, multi-stage heat pump system which crosses the pinch located at $-8^{\circ} \mathrm{C}$.

(b) An ethylene plant separation train [71] discussed by Colmenares and Seider [25] was chosen due to the refrigeration needs at extremely low temperatures $\left(-115^{\circ} \mathrm{C}\right)$ as shown in Figure $3(\mathrm{~b})$. The pinch point is located at approximately $130{ }^{\circ} \mathrm{C}$, which leaves little room for a heat pump crossing the pinch. Vaidyaraman and Maranas [30] discussed a slightly modified version of the same problem (different $\Delta \mathrm{T}_{\text {min }}$ ) with higher total cost, which is not treated here. 
(c) A Cold Tray distillation sequence presented by Colmenares and Seider [31] and later studied by Swaney [53] was selected to revisit the original solution which disregarded an obvious improvement of heat pumping across the process pinch $\left(\approx 60{ }^{\circ} \mathrm{C}\right)$. Figure $3(\mathrm{c})$ shows the process temperature enthalpy profile indicating the process thermal demands and pinch point. Swaney [53] considered a solution with heat pumping across the process pinch for this case study, however with modified input data (isentropic compressor efficiency of 0.8) and is, therefore, not considered here.

The literature optimal cases were reproduced by adding constraints at the slave level of the HPS to force the resulting heat pump layout to contain the same features and operating conditions as those presented in the literature. This was achieved by pre-selecting temperature levels and fixing the active compressor stages and fluids. In this way, the HPS flexibility was tested and reference values for later comparison were calculated, given that most literature studies used different thermodynamic property calculations.

An analysis of the original and the reproduced data (referred to as Reference since they serve for later comparison) is presented in Table 5 . The results are compared based on the TAC which was the objective function in the literature. It was observed that the results from literature cases E2 and Cold Tray could be reproduced with a negligible difference (below $+/-1 \%$ ) in each of the categories including the TAC. The slight difference in results is explained by different property calculation methods. Reproduction of the Ethylene case generated around $23 \%$ higher electricity consumption which resulted in $22 \%$ higher TAC. The thermodynamic conditions are quite extreme (very low temperature) and thus advanced property estimations are necessary. The literature case consists of five cascaded heat pump cycles over a wide temperature range. Even small underestimation or overestimation of the electricity consumption in the lower cycles is therefore cascaded over the entire range. This, in combination with the property estimation methods, could explain the discrepancy.

\subsection{Optimization}

In this section, the generic HPS and multi-objective solution strategy were applied to the three literature cases. Parameters of the master level optimization are presented in appendix A.2. The MOGA algorithm was terminated after $10^{5}$ function evaluations if the convergence criterion of 0.1 percent change in the non-dominated frontier was not reached. Multi-objective optimization
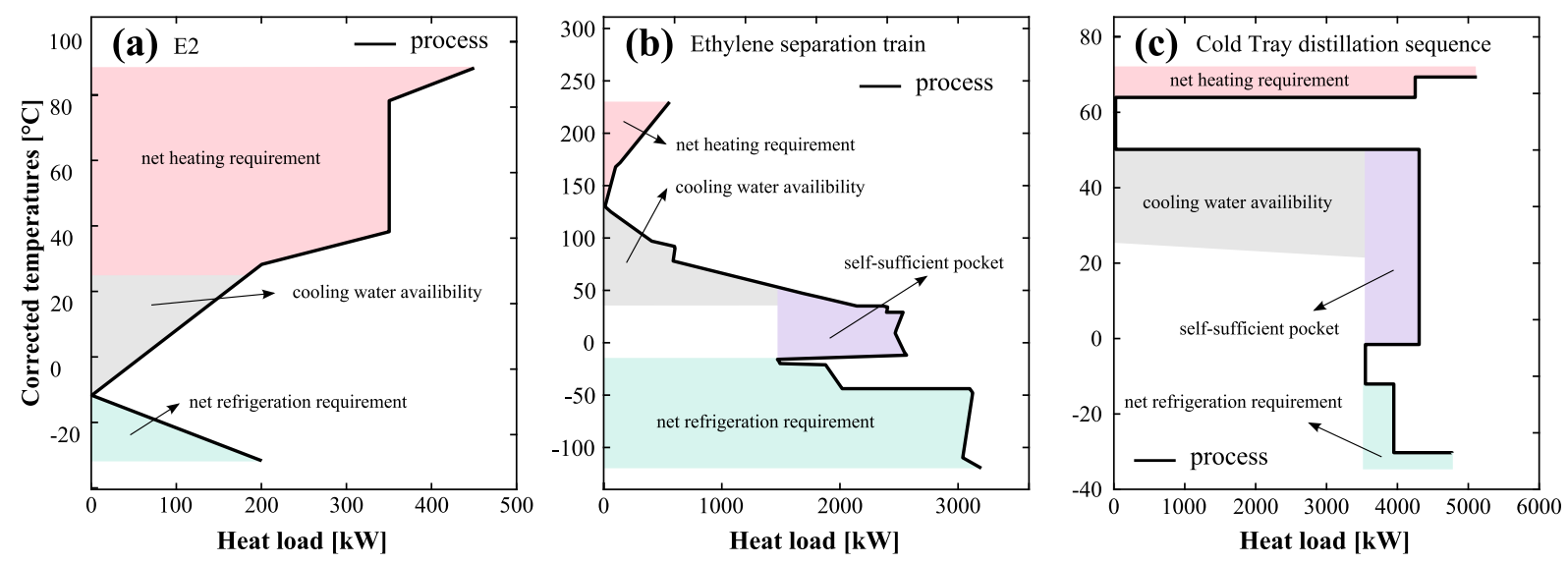

Figure 3: Grand composite curves (temperature enthalpy profiles) from process thermal streams of three benchmark cases, reproduced from (a) Shelton and Grossmann [24], (b) Lincoff et al. [71], (c) Colmenares and Seider [31], respectively. 
Table 5: Comparison of original data and data reproduced (Reference) in this work with the HPS. A detailed description of the parameters is presented in Appendix B.1.

\begin{tabular}{|c|c|c|c|c|c|c|c|c|c|c|}
\hline & & \multicolumn{3}{|c|}{ E2 } & \multicolumn{3}{|c|}{ Ethylene } & \multicolumn{3}{|c|}{ Cold Tray } \\
\hline & & Original [23] & Reference & $\Delta$ & Original [25] & Reference & $\Delta$ & Original [31] & Reference & $\Delta$ \\
\hline \multicolumn{11}{|l|}{ Opex } \\
\hline Cooling water & $\$ / y$ & 0 & 0 & - & $23^{\prime} 950$ & $25^{\prime} 020$ & $4.5 \%$ & $299^{\prime} 950$ & $29^{\prime} 930$ & $-0.1 \%$ \\
\hline Steam & $\$ / y$ & $10^{\prime} 440$ & $10^{\prime} 460$ & $0.2 \%$ & - & - & - & $287^{\prime} 100$ & $287^{\prime} 090$ & $0.0 \%$ \\
\hline Electricity & $\$ / y$ & $27^{\prime} 370$ & $27^{\prime} 620$ & $0.9 \%$ & $266^{\prime} 080$ & $327^{\prime} 580$ & $23.1 \%$ & $97^{\prime} 260$ & $96 ׳ 370$ & $-0.9 \%$ \\
\hline \multicolumn{11}{|l|}{ Capex } \\
\hline
\end{tabular}

was carried out with regard to the two competing objectives being the opex and capex. The saturation temperature levels and sub-cooling temperature differences (only in case E2) were the variables at the master level. Due to the more or less constant temperature requirements in the Ethylene and Cold Tray case studies, liquid subcooling and gas-cooling were not considered here. However, for these two cases, fluid selection was considered following the data from the literature $[25,31]$. To investigate the potential for cascaded cycles, the set of candidate fluids was added at the slave level.

Input data and variable boundaries to the different cases are presented in appendix B.1. Figures 4(a),5(a),6(a) show the results from the multi-objective optimization. The minimum TAC point of each case was selected and compared to the Reference case in an integrated temperature enthalpy diagram in Figures 4(b),5(b),6(b) in addition to the flowcharts in Figure 7. The three cases are each discussed in the next paragraphs.

Temperature ranges, E2 The multi-objective results in Figure 4(a) exhibit a pattern of diagonal lines with interstitial gaps. These lines can be explained by the differing numbers of compressors. A trade-off is constituted between a reduction of opex by multi-stage compression, and an increase in capex related to a higher number of compressors with their associated variable and fixed investment costs. The number of compressors for solutions in the non-dominated frontier between opex and capex ranges from three to six. Minimum TAC was achieved with four compressors in contrast to the six suggested in the Reference. One additional advantage of this multi-objective optimization approach is also that sub-optimal solutions with lower system complexity can be identified. The best solution with three compressors e.g. bears similar TAC $(<+1 \%)$ as the overall minimum cost solution with four compressors and may therefore be a better solution from the practical perspective. The HPS allows for a comprehensive analysis of heat pump features and operating conditions. The proposed minimum TAC solution consists of a heat pump with inter-cooling, subcooling, and gas-cooling heat exchangers as depicted in Figure 4(b) and Figure 7(a) which contribute to achieving similar performance (in terms of opex) at reduced compressor fixed costs capex compared to the Reference. This leads to a potential overall $5 \%$ reduction in TAC as displayed in Table 6.

Cascaded cycles, Ethylene separation train Results from the multi-objective optimization in Figure 5(a) show that the two objective functions, opex and capex, are not conflicting. Two main reasons were identified: (1) Due to the elevated process pinch point at $130^{\circ} \mathrm{C}$, a pinch-crossing heat pump (as presented in case E2) is not feasible, thus there is no trade-off between (higher) compressor investment (capex) and (lower) hot utility requirements (opex); (2) The fixed investment costs of the compressors are distinctly smaller than the proportional costs which translates to the heat pump capex depending primarily on the electricity consumption (opex). Thus all objectives point in the same direction, which would make a Single Objec- 

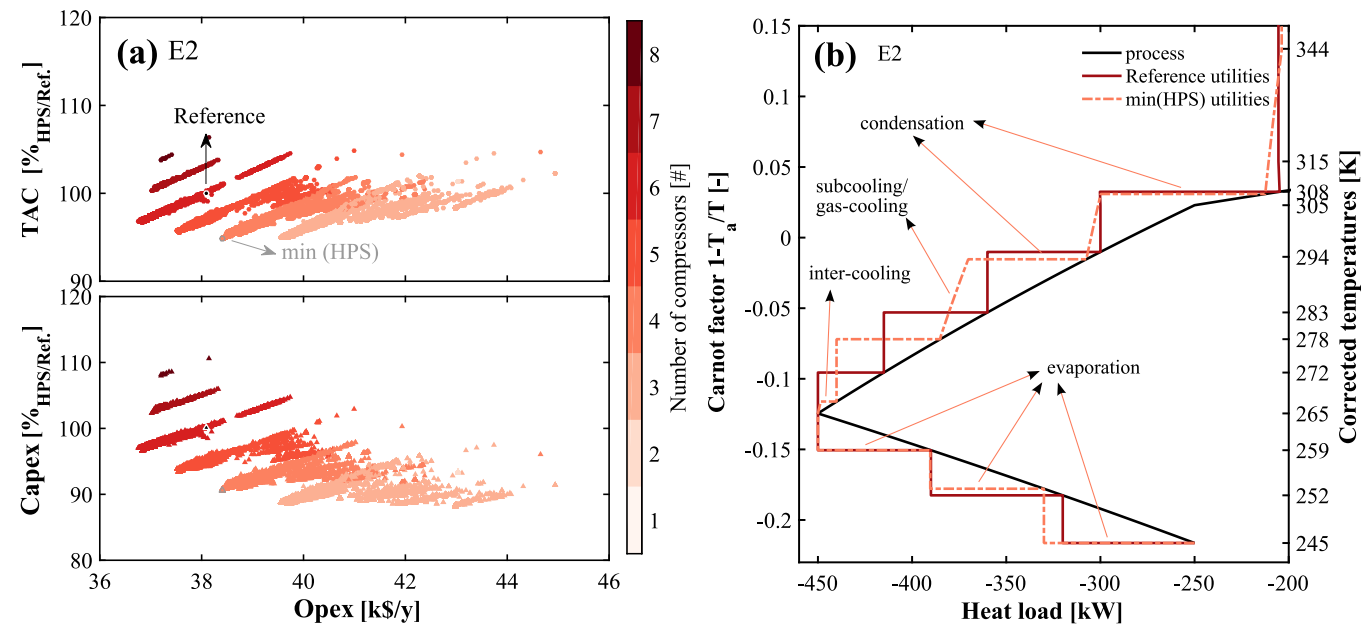

Figure 4: E2. (a) Multi-objective results, (b) integrated composite curves (Carnot factor enthalpy profiles) of Reference and min(HPS). Termination: 100k iterations (961 generations); last 50'000 iterations displayed.
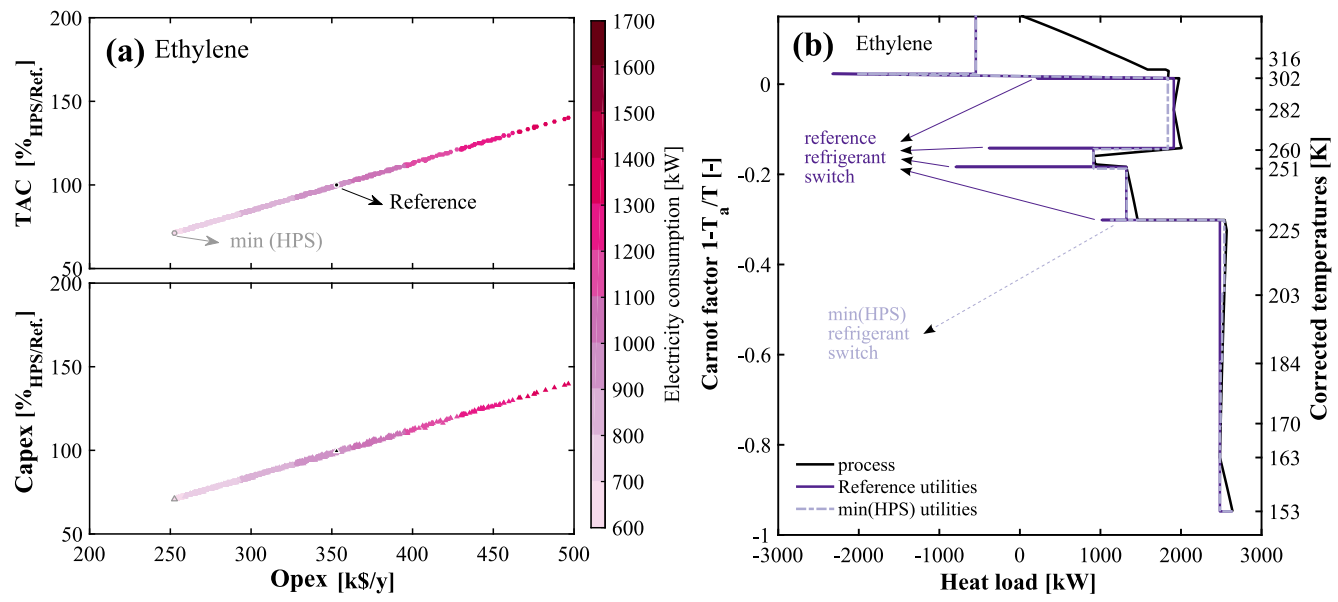

Figure 5: Ethylene. (a) Multi-objective results, (b) integrated composite curves. Termination: 118 generations; all 2'852 iterations displayed.
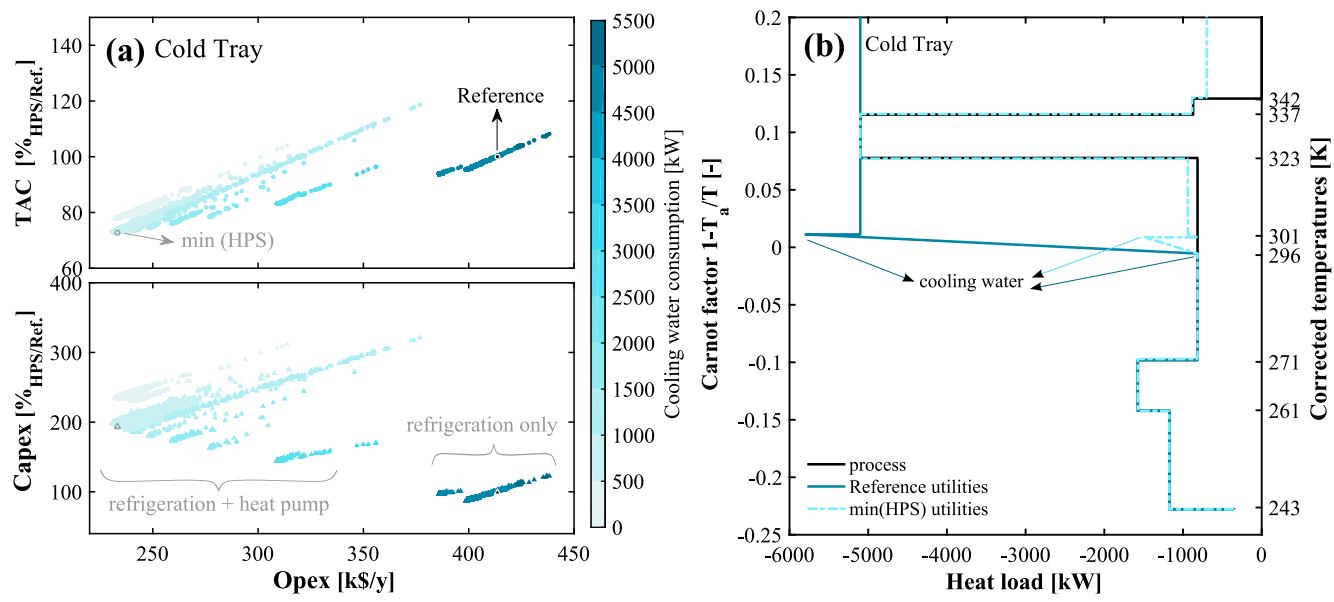

Figure 6: Cold Tray. (a) Multi-objective results, (b) integrated composite curves. Termination: 100k iterations (229 generations); last 50'000 iterations displayed. 
tive Genetic Algorithm (SOGA) [65] more appropriate. Running SOGA led to an equivalent result. The minimum point reveals an approximate $30 \%$ reduction in the TAC compared to the Reference (shown in Table 6) driven by the drastically diminished electricity consumption. As illustrated in Figure 5(b) and Figure 7(b), the power consumption was reduced due to a decrease in number of refrigerant switches from four to one, which avoided the minimum temperature difference $\left(\mathrm{DT}_{\min }=10 \mathrm{~K}\right)$ in the switching heat exchangers. Inter-cooling at three levels $(174.5 \mathrm{~K}, 189.5 \mathrm{~K}, 208.5 \mathrm{~K})$ additionally improved the refrigerator performance leading to an improvement of the COP from 1.8 to 2.6. Due to the constraint on the compression ratio (unlike in the original) to be below 10, which may still be extremely high, the compressor is changed at $180.5 \mathrm{~K}$. This leads to a more complicated, however, beneficial flow management to saturate the superheated compressor outlet.
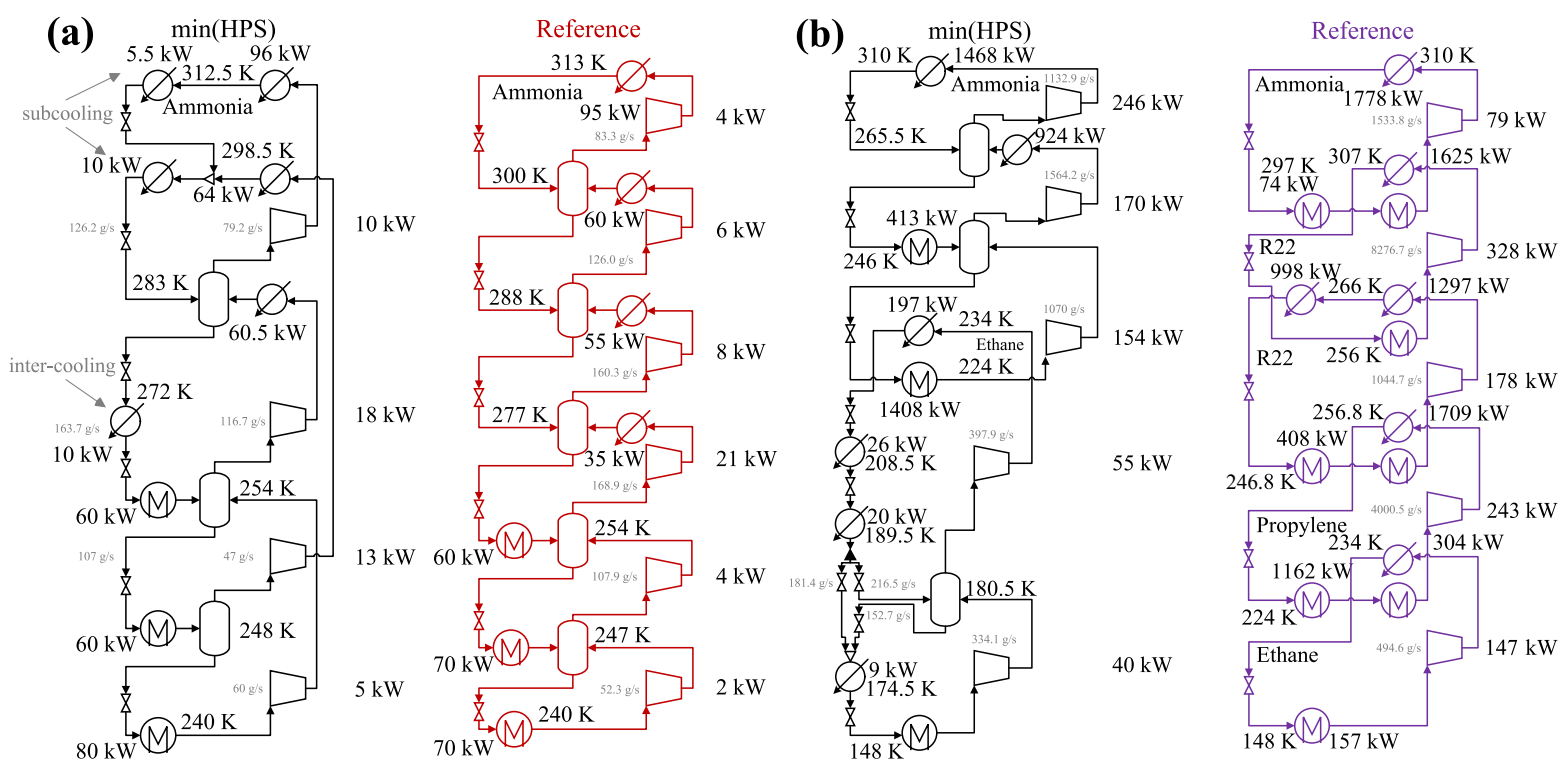

(c)

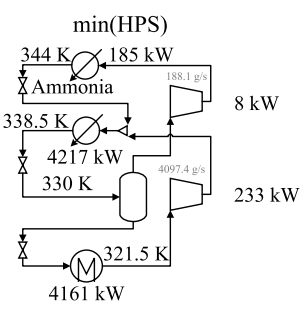

Reference

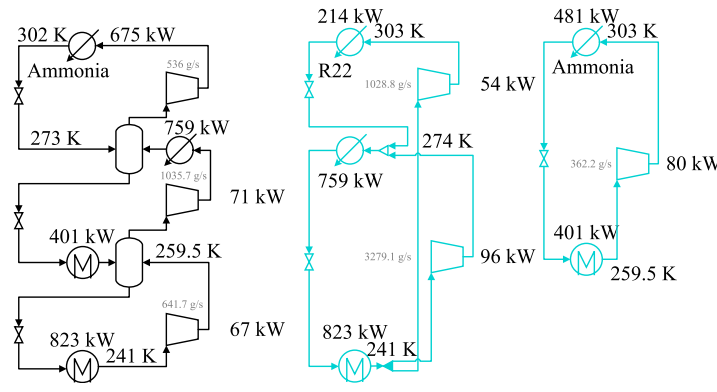

Figure 7: Flowchart of the optimal HPS heat pump designs (a) E2, (b) Ethylene, (c) Cold Tray of benchmark analysis. 
Table 6: Optimization results. Data shown as Reference was generated with HPS based on the respective literature input data (Section 4.1).

\begin{tabular}{|c|c|c|c|c|c|c|c|}
\hline & & \multicolumn{2}{|c|}{$E 2$} & \multicolumn{2}{|c|}{ Ethylene } & \multicolumn{2}{|c|}{ Cold Tray } \\
\hline & & Reference & $\min (\mathrm{HPS})$ & Reference & $\min (\mathrm{HPS})$ & Reference & $\min (\mathrm{HPS})$ \\
\hline \multicolumn{8}{|l|}{ Opex } \\
\hline Cooling water & $\$ / y$ & 0 & 0 & 25,020 & 23,150 & 29,930 & 4,810 \\
\hline Steam & $\$ / y$ & 10,460 & 10,370 & 0 & 0 & 287,090 & 39,310 \\
\hline Electricity & $\$ / y$ & 27,620 & 28,040 & 327,580 & 223,340 & 96,370 & 189,900 \\
\hline \multicolumn{8}{|l|}{ Capex } \\
\hline No. of compressors & \# & 6 & 4 & 5 & 5 & 3 & 5 \\
\hline Compressors & $\$ / y$ & 54,710 & 49,630 & 230,810 & 159,140 & 56,380 & 109,220 \\
\hline TAC & $\$ / y$ & 92,790 & 88,050 & 583,410 & 405,630 & 469,770 & 343,230 \\
\hline Improvement & $\%$ & 0 & $5.1 \%$ & $0 \%$ & $30.5 \%$ & $0 \%$ & $26.9 \%$ \\
\hline $\mathrm{COP}_{\text {refrigeration }}$ & - & 4.4 & 4.3 & 1.8 & 2.6 & 5.3 & 5.8 \\
\hline
\end{tabular}

Process pinch point, Cold Tray distillation Results from the multi-objective optimization in Figure 6(a) indicate a pattern of diagonal lines with gaps in between. Unlike case E2 this is unrelated to the number of compressors in the system, which are mostly at their maximum (five) due to low compressor fix cost. However, it can be observed that the cooling water consumption correlates with the formation of lines. At highest opex, the largest amount of cooling water is consumed. It is used to cool the process and the refrigeration cycle as reported in the Reference displayed in Figure 6(b) and Figure 7(c). By adding a heat pump around the process pinch, the cooling water and hot utility consumptions were drastically reduced. The increase in capex is off-set by a larger decrease in opex leading to a maximum reduction of $27 \%$ in TAC in the best point, as depicted in Table 6 . The HPS minimum TAC solution consists of two separate (ammonia based) heat pump systems, one satisfying the refrigeration needs (three compressors), and one across the process pinch (see Figure 7(c) and Figure 6(b), two compressors). With the refrigeration configuration a lower cost, higher COP solution could be derived compared to the reference case which consists of two separate heat pump cycles (R-22 (two compressors) and ammonia). The integrated composite curves in Figure 6(b) show that the HPS solution with the pinch heat pump not only reduces cost, but also exergy losses (proportional to the area between the curves) of the system.

Synthesis In conclusion, the HPS can represent a wide range of heat pump features and cycle architectures, while at the same time providing improved solutions to different literature optimal cases. This is attributed to a wider range of heat pump features considered and variable temperature level selection. As demonstrated, the level of complexity, variety of heat pump features considered, and technical constraints added depends on the choice of the user, which makes the superstructure flexible to handle. The solution strategy allows to generate a set of non-dominated solutions which enable the user to perform further analysis, thereby gaining deeper insight to the problem, and to apply other selection criteria. The literature cases discussed in this section serve for benchmarking the underlying approach, however, important criteria are neglected, such as HEN costs, compressor isentropic efficiencies, "real" utilities, and technical constraints thus generating "theoretical" solutions. In the next section 4.3, an extended version of the presented case E2 is, therefore, discussed. 


\subsection{Extended analysis}

The heat pump system for the extended case E2 was optimized with respect to opex and capex assuming an isentropic compressor efficiency of $70 \%$, a maximum compression ratio of 8 [bar/bar] in each compressor, and HEN cost estimation functions from the literature (section 3.3.1, Table 3). All input data is reported in appendix B.2.

\subsubsection{Fluid selection}

The choice of fluids considered for the extended case E2 was based on the critical temperature $\left(T_{\text {crit }} \geq 40^{\circ} \mathrm{C}\right)$, the boiling point $\left(T_{\text {boil }} \leq-33^{\circ} \mathrm{C}\right)$, and the global warming potential (GWP $\leq$ $\left.4 \cdot 10^{3}\right)$. The fluid investment cost was not considered in this analysis. An interactive parallel coordinate visualization tool developed by Kermani et al. [72] was used to facilitate the fluid screening step which led to ten relevant fluids (see results in Figure 8a and Figure 14). Both fluid selection methods described in section 3.4 were applied and compared during this analysis. To ensure reasonable propagation of the MOGA algorithm during fluid selection at the slave level, a time limit of 600 seconds was imposed for the MILP solver. If the limit is reached, the solver returns the best integer solution at that point even if it is above the specified optimality gap. Nevertheless, a total of 25000 MOGA iterations required higher computational time than 100000 iterations with master level fluid selection.

Figure $8 \mathrm{~b}$ shows the non-dominated frontiers of the different fluids generated over all MOGA iterations by both fluid selection methods. The results from the slave level selection (after intense computational effort) are dominated by the frontier of the master level selection, and it is thus concluded that if not necessary (e.g. for studying cascaded cycles) this method should be avoided. In the master level selection, propane dominates the other fluids over the entire range of solutions. This outcome was reproduced multiple times by rerunning MOGA with different seeds. Since the MOGA algorithm is aimed at improving the global non-dominated frontier, the frontier of propane yields a good approximation of the global Pareto curve for this

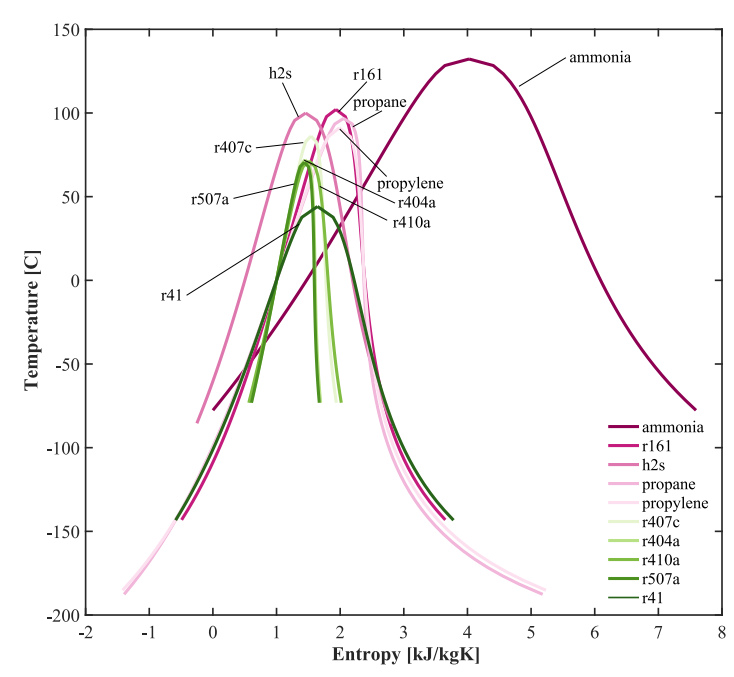

(a) Vapor-liquid saturation curves of selected fluids in temperature entropy diagram.

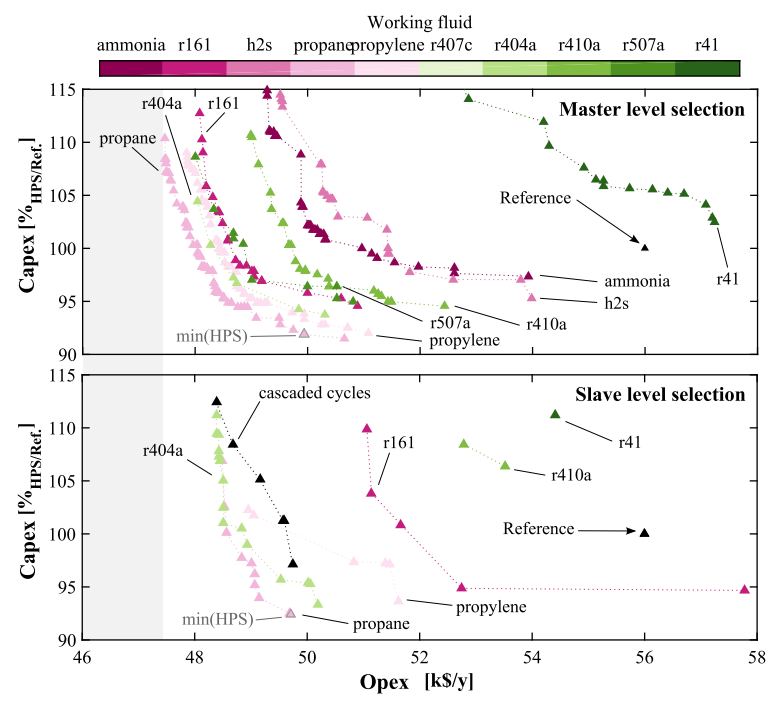

(b) Top: Selection at master level; 100k iterations, $211 \mathrm{k}$ sec. Bottom: Selection at slave level; 25k iterations, 890k sec.

Figure 8: (a) Fluid set and (b) multi-objective optimization results. In black: multi-fluid solution. R407c is not present, due to a Coolprop [56] problem with this fluid. 
case. The minimum TAC solution generated a total reduction of approximately $9.5 \%$. This solution consists of three compressors between -33 and $41.5^{\circ} \mathrm{C}$ with propane as working fluid (see Figure 15).

To study the dominance of propane over the other fluids, the minimum TAC solution was investigated more closely. Therefore, the fraction $\Delta \mathrm{Q}^{\mathrm{ref}}\left(\mathrm{T}_{2}\right) / \Delta \mathrm{E}^{\mathrm{comp}, 2 \rightarrow 1}$ between evaporation enthalpy and compressor power amidst the two saturation temperature levels $T_{1}$ and $T_{2}$ of the first compressor was calculated for all fluids. Figure 9 shows the fraction versus the slope of the entropy vapor saturation curve $\Delta \mathrm{s} / \Delta \mathrm{T}=\left(\mathrm{s}_{v}\left(\mathrm{~T}_{1}\right)-\mathrm{s}_{v}\left(\mathrm{~T}_{2}\right)\right) /\left(\mathrm{T}_{1}-\mathrm{T}_{2}\right)$. Figure 9a reveals that the compression work correlates with the slope $\Delta \mathrm{s} / \Delta \mathrm{T}$. Propane is among the fluids which show the most isentropic behavior $(\Delta \mathrm{s} / \Delta \mathrm{T} \approx 0)$ which leads to lower compression work and therefore a higher fraction $\Delta \mathrm{Q} / \Delta \mathrm{E}$. When calculating the fraction based on the enthalpy of a complete evaporation (as done in Figure 9a), propane is outperformed by r404a and r507a. In a real system, however, irreversibilities related to the expansion work will prevent complete evaporation. Accounting also for those irreversibilities, as shown in Figure 9b, propane yields the highest fraction $\Delta \mathrm{Q} / \Delta \mathrm{E}$ hence exhibiting ideal thermodynamic properties in this temperature range. Comparing the sequence of fluid frontiers (from Figure 8b, top) to the thermodynamic performance (Figure 9b) indicates a close agreement between thermodynamic and economic performance, which will be further investigated. The closest competitors to propane were: propylene, r161, r404a, r410a, and r507a. Ammonia and hydrogen sulfide generated higher-cost solutions, still strongly outperforming r41. All solutions (except r41) outperform the solution presented by the reference case updated with equivalent input data. The dominance of propane over the entire solution space agrees with other reports indicating superior performance in that temperature range [73]. Further fluid selection criteria could include safety factors (such as flammability or toxicity), fluid cost, ozone layer depletion potential (ODP), global warming potential (GWP) and heat transfer characteristics. Each of these criteria would favor different refrigerants and thus the filtering of potential solutions should be completed carefully to find the best solution for a given case.

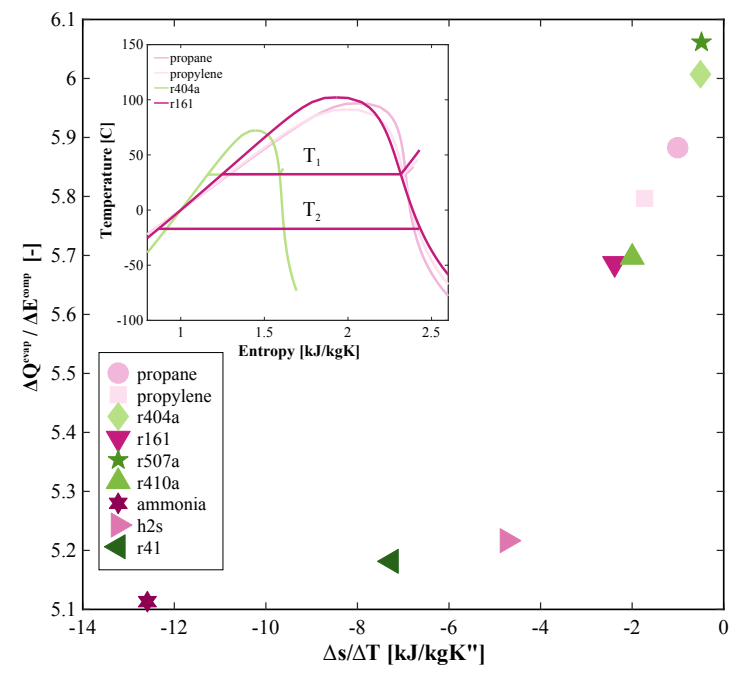

(a) Complete evaporation.

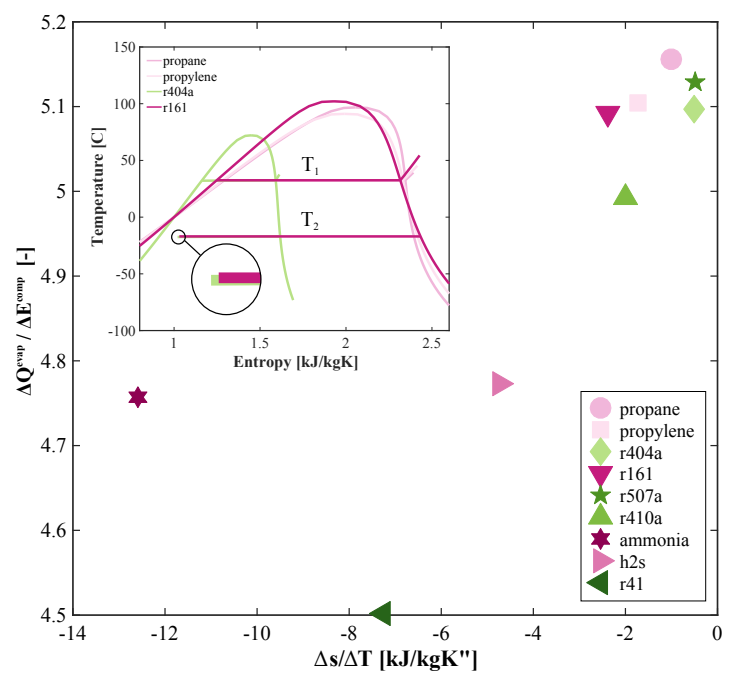

(b) Incomplete evaporation, considering isenthalpic expansion from the level above $\left(8^{\circ} \mathrm{C}\right.$ with $5 \mathrm{~K}$ subccoling).

Figure 9: Compressor between saturation levels $\mathrm{T}_{1}\left(32.5^{\circ} \mathrm{C}\right)$ and $\mathrm{T}_{2}\left(-17^{\circ} \mathrm{C}\right)$. 


\subsubsection{COP, cycle complexity \& HEN costs}

Figure 10 illustrates the final non-dominated frontier of the results from the master level fluid selection including several properties of these solutions. The (cold) COP increases with decreasing opex, thus, reduced electricity consumption at increased number of compressors; the difference between the lowest (2.9) COP and highest (3.3) is achieved through a higher number of compression stages, increased subcooling and gas-cooling. The highest reduction in TAC $(-9.5 \%)$ was achieved with opex of $49.9 \mathrm{k} \$$ (from Figure $8 \mathrm{~b}$, top). It can be further noted that the entire frontier spans a relatively small range of operating costs. This is attributed to the simple problem formulation of this benchmark case. In Figure 10, the expected inverse relationship between opex and HEN costs is clearly visible which is impacted by two main factors. The first factor relates to activation of gas-cooling. Since the heat transfer coefficients of gases are distinctly lower than those of condensing fluids, recuperation of sensible heat contained in superheated vapor requires more heat exchange area and therefore increases the HEN costs. The second factor increasing HEN cost is related to a higher number of compression stages, which implies installation of more heat exchangers; thus, influencing both opex and capex. It is also observed that the amount of subcooling increases in tandem with the COP thus providing another option for improving operational efficiency with increased investment. Subcooling was activated in the minimum TAC solution which indicates that its advantageous characteristics should not be overlooked in cycle design. A HEN design of the reference and minimum TAC case was conducted (as shown in B.2, Figure 16). The optimal solution requires one more heat exchanger than the reference case which is mildly penalized by the HEN cost function thereby being outweighed by the benefits of the reduced opex. The HEN cost estimation from the area targeting compares satisfactorily to the actual design with an overestimation between $8-11 \%$ (optimal case design: 53.6, estimation: $57.8 \mathrm{k} \$ / \mathrm{y}$; reference case design: 52.8, estimation: 58.8 $\mathrm{k} \$ / \mathrm{y}$ ). Likewise compares the total estimated area and the minimum number of heat exchangers.

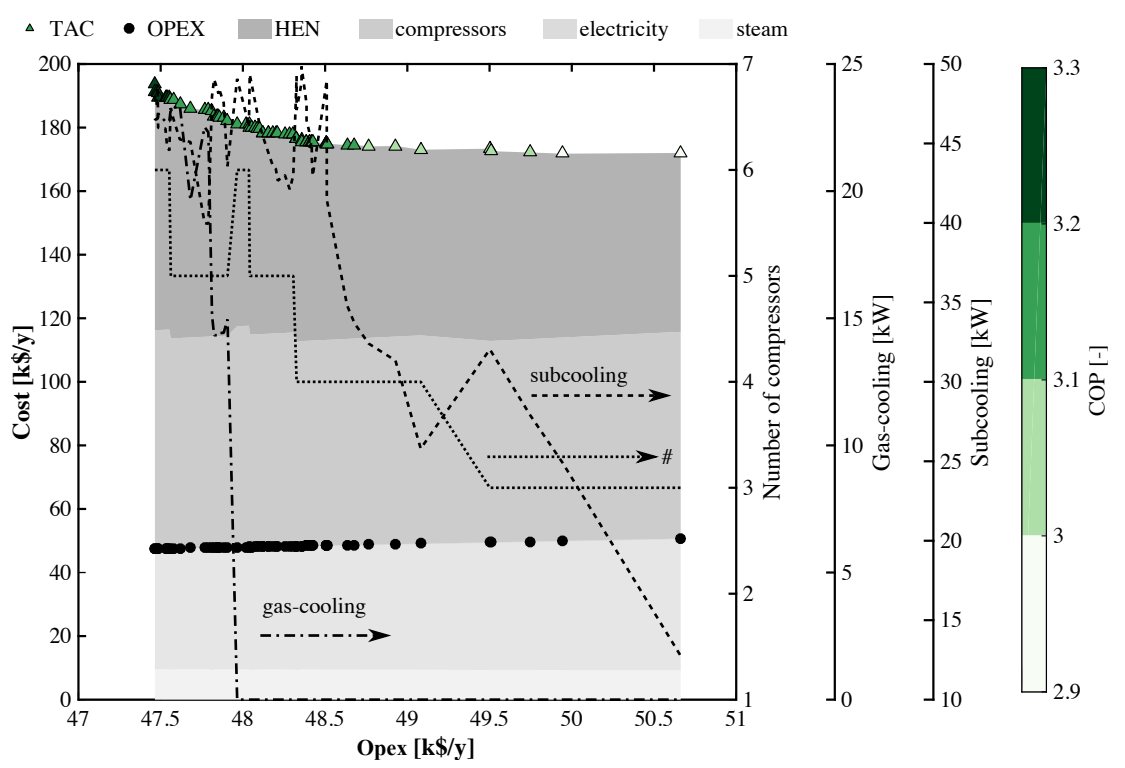

Figure 10: Overall non-dominated frontier of MOGA results from master level fluid selection. 


\section{Conclusions}

This study has presented a mathematical approach for optimal design of industrial heat pumps spanning a wide variable solution space. The method provides a framework for deriving utility targets, including optimal heat pump component sizes and operating conditions. This provides a basis for detailed system design in a subsequent step to account for dynamics and off-design operation.

The novel superstructure-based synthesis method is embedded in a computational framework and is solved in a decomposition approach. A comprehensive list of heat pump features are taken into account while technical limitations are considered and a set of solutions is provided which allows for expert-based decision making and further in-depth analysis of the solutions.

For benchmarking, the method was compared to a set of literature cases generating between 5 and $30 \%$ cost improvements to the optimal solutions reported. An extended version of one case is presented considering fluid selection, HEN cost estimations, and technical constraints within the problem formulation. The extended case highlights a trade-off between energy efficiency and system complexity expressed by the increase of heat exchanger network costs with the number of compression stages, level of gas-cooling and subcooling which all improve the COP. This is especially evident when comparing the solutions with 3 and 5 compression stages causing an increase of the COP from 2.9 to 3.1 at $3 \%$ increase in TAC. Fluid selection was successfully performed indicating that propane is the most favorable fluid both in economic and thermodynamic terms in this temperature range. The HPS proves to be flexible for different requirements serving in a variety of cases. It has to be noted that a comprehensive analysis of an industrial process should always comprehend optimization of the entire utility network, including the hot utilities. This was neglected in this work to be in accordance with the literature input data. In subsequent analysis, the trade-off with other utility technologies should be considered. Future work should also include supercritical cycles, refined fluid and component selection strategies, as well as consideration of off-design performance in multi-time problems.

\section{Acknowledgements}

The authors acknowledge the support of Swiss Federal Office of Energy SFOE (Grant SI/50148701). The research project was further financially supported by the Swiss Innovation Agency Innosuisse and is part of the Swiss Competence Center for Energy Research SCCER EIP Efficiency of Industrial Processes.

\section{References}

[1] IEA. Application of Industrial Heat Pumps: Executive Summary, 2014. URL http://heatpumpingtechnologies.org/publications/ application-of-industrial-heat-pumps-executive-summary/.

[2] K. J. Chua, S. K. Chou, and W. M. Yang. Advances in heat pump systems: A review. Applied Energy, 87(12):3611-3624, 2010. ISSN 0306-2619. doi: 10.1016/j.apenergy.2010.06. 014. URL http://www. sciencedirect.com/science/article/pii/S030626191000228X.

[3] H.J. Laue. Annex 35 Final Report - Application of Industrial Heat Pumps, Part 1. Technical report, IEA, 2014. URL http://heatpumpingtechnologies.org/publications/ application-of-industrial-heat-pumps-part-2/. 
[4] Cordin Arpagaus, Frederic Bless, Jürg Schiffmann, and Stefan S. Bertsch. Multitemperature heat pumps: A literature review. International Journal of Refrigeration, 69:437-465, September 2016. ISSN 0140-7007. doi: 10.1016/j.ijrefrig.2016.05.014. URL http://www.sciencedirect.com/science/article/pii/S0140700716301190.

[5] Xudong Wang, Yunho Hwang, and Reinhard Radermacher. Two-stage heat pump system with vapor-injected scroll compressor using R410a as a refrigerant. International Journal of Refrigeration, 32(6):1442-1451, September 2009. ISSN 0140-7007. doi: 10.1016/j.ijrefrig.2009.03.004. URL http://www.sciencedirect.com/science/article/ $\mathrm{pii} / \mathrm{S} 0140700709000814$.

[6] J. Schiffmann. Integrated Design and Multi-objective Optimization of a Single Stage HeatPump Turbocompressor. Journal of Turbomachinery, 137(7):071002-071002-9, July 2015. ISSN 0889-504X. doi: 10.1115/1.4029123. URL http://dx.doi.org/10.1115/1.4029123.

[7] F.J. Barnés and C.J. King. Synthesis of cascade refrigeration and liquefaction systems. Industrial and Engineering Chemistry: Process Design and Development, 13(4):421-433, 1974. ISSN 0019-7882.

[8] W.B. Cheng and R.S.H. Mah. Interactive synthesis of cascade refrigeration systems. Industrial 83 Engineering Chemistry Process Design and Development, 19(3):410-420, 1980. ISSN 0196-4305.

[9] Bodo Linnhoff and John R. Flower. Synthesis of heat exchanger networks: I. Systematic generation of energy optimal networks. AIChE Journal, 24(4):633-642, July 1978. ISSN 1547-5905. doi: 10.1002/aic.690240411. URL http://onlinelibrary.wiley.com/doi/ 10.1002/aic.690240411/abstract.

[10] Ian C. Kemp. Pinch Analysis and Process Integration: A User Guide on Process Integration for the Efficient Use of Energy. Butterworth-Heinemann, April 2011. ISBN 978-0-08046826-6. Google-Books-ID: gQMxilJQmV4C.

[11] D. W. Townsend and Bodo Linnhoff. Heat and power networks in process design. Part II: Design procedure for equipment selection and process matching. AIChE Journal, 29 (5):748-771, September 1983. ISSN 1547-5905. doi: 10.1002/aic.690290509. URL http: //onlinelibrary.wiley.com/doi/10.1002/aic.690290509/abstract.

[12] Saidas M. Ranade. New insights on optimal integration of heat pumps in industrial sites. Heat Recovery Systems and CHP, 8(3):255-263, January 1988. ISSN 0890-4332. doi: 10. 1016/0890-4332(88)90061-0. URL http://www.sciencedirect.com/science/article/ pii/0890433288900610.

[13] Michele Zehnder. Efficient air-water heat pumps for high temperature lift residential heating, including oil migration aspects. 2004. doi: 10.5075/epfl-thesis-2998,urn:nbn:ch: bel-epfl-thesis2998-6. URL https://infoscience.epfl.ch/record/33470.

[14] H. Sato, Y. Kimata, Y. Hotta, T. Goto, H. Mizuno, and H. Kobayashi. Development of two-stage compressor for CO2 heat-pump water heaters. Mitsubishi Heavy Ind Tech Rev, 49:92-97, 2012.

[15] Wilbert F. Stoecker. Industrial refrigeration handbook. McGraw-Hill, New York, vol 10 edition, 1998. URL http://library.wur.nl/WebQuery/clc/977739. 
[16] Tomoichiro Tamura, Yuuichi Yakumaru, and Fumitoshi Nishiwaki. Experimental study on automotive cooling and heating air conditioning system using $\mathrm{CO} 2$ as a refrigerant. International Journal of Refrigeration, 28(8):1302-1307, 2005. ISSN 0140-7007. doi: 10.1016/j.ijrefrig.2005.09.010. URL http://www.sciencedirect.com/science/article/ $\mathrm{pii/S0140700705001829.}$

[17] Matej Visek, Cesare Maria Joppolo, Luca Molinaroli, and Andrea Olivani. Advanced sequential dual evaporator domestic refrigerator/freezer: System energy optimization. International Journal of Refrigeration, 43:71-79, July 2014. ISSN 0140-7007. doi: 10.1016/j.ijrefrig.2014.03.001. URL http://www.sciencedirect.com/science/article/ $\mathrm{pii/S0140700714000486.}$

[18] Chieko Kondou and Shigeru Koyama. Thermodynamic Assessment of High-Temperature Heat Pumps for Heat Recovery. International Refrigeration and Air Conditioning Conference, January 2014. URL http://docs.lib.purdue.edu/iracc/1408.

[19] Petter Nekså, Håvard Rekstad, G. Reza Zakeri, and Per Arne Schiefloe. CO2-heat pump water heater: characteristics, system design and experimental results. International Journal of Refrigeration, 21(3):172-179, 1998. ISSN 0140-7007. doi: 10.1016/ S0140-7007(98)00017-6. URL http://www.sciencedirect.com/science/article/pii/ S0140700798000176.

[20] M. Elakdhar, E. Nehdi, and L. Kairouani. Analysis of a Compression/Ejection Cycle for Domestic Refrigeration. Industrial \& Engineering Chemistry Research, 46(13):4639-4644, June 2007. ISSN 0888-5885. doi: 10.1021/ie070377e. URL http://dx.doi.org/10.1021/ ie070377e.

[21] Hiroshi Oshitani, Yasushi Yamanaka, Hirotsugu Takeuchi, Katsuya Kusano, Makoto Ikegami, Yoshiaki Takano, Naohisa Ishizaka, and Takayuki Sugiura. Vapor compression cycle having ejector. Patent US7254961 B2, August 2007. URL http://www.google.com/ patents/US7254961.

[22] Hiroshi Oshitani, Hirotsugu Takeuchi, Etsuhisa Yamada, and Haruyuki Nishijima. Ejectortype refrigerant cycle device. Patent US8186180 B2, May 2012. URL http://www .google. ch/patents/US8186180.

[23] M. R. Shelton and I. E. Grossmann. Optimal synthesis of integrated refrigeration systems I. Mixed-integer programming model. Computers 83 Chemical Engineering, 10(5):445459, January 1986. ISSN 0098-1354. doi: 10.1016/0098-1354(86)85014-1. URL http: //www.sciencedirect.com/science/article/pii/0098135486850141.

[24] M. R. Shelton and I. E. Grossmann. Optimal synthesis of integrated refrigeration systems II. Implicit enumeration scheme. Computers \& Chemical Engineering, 10(5):461477, January 1986. ISSN 0098-1354. doi: 10.1016/0098-1354(86)85015-3. URL http: //www.sciencedirect.com/science/article/pii/0098135486850153.

[25] T. R. Colmenares and W. D. Seider. Synthesis of cascade refrigeration systems integrated with chemical processes. Computers \& Chemical Engineering, 13(3):247-258, 1989. ISSN 0098-1354. doi: 10.1016/0098-1354(89)85002-1. URL http://www. sciencedirect.com/ science/article/pii/0098135489850021. 
[26] Audun Aspelund, David Olsson Berstad, and Truls Gundersen. An Extended Pinch Analysis and Design procedure utilizing pressure based exergy for subambient cooling. Applied Thermal Engineering, 27(16):2633-2649, November 2007. ISSN 1359-4311. doi: 10.1016/j.applthermaleng.2007.04.017. URL http://www.sciencedirect.com/science/ article/pii/S1359431107001627.

[27] Helen Carla Becker. Methodology and Thermo-Economic Optimization for Integration of Industrial Heat Pumps. PhD thesis, 2012.

[28] Gbemi Oluleye, Megan Jobson, Robin Smith, and Simon J. Perry. Evaluating the potential of process sites for waste heat recovery. Applied Energy, 161:627-646, January 2016. ISSN 0306-2619. doi: 10.1016/j.apenergy.2015.07.011. URL http://www.sciencedirect.com/ science/article/pii/S0306261915008405.

[29] Meysam Kamalinejad, Majid Amidpour, and S. M. Mousavi Naeynian. Thermodynamic design of a cascade refrigeration system of liquefied natural gas by applying mixed integer non-linear programming. Chinese Journal of Chemical Engineering, 23(6):998-1008, June 2015. ISSN 1004-9541. doi: 10.1016/j.cjche.2014.05.023. URL //www.sciencedirect. com/science/article/pii/S1004954115000397.

[30] Shankar Vaidyaraman and Costas D. Maranas. Optimal synthesis of refrigeration cycles and selection of refrigerants. AIChE Journal, 45(5):997-1017, 1999. ISSN 15475905. doi: 10.1002/aic.690450510. URL http://onlinelibrary.wiley.com/doi/10. 1002/aic.690450510/abstract.

[31] T. R. Colmenares and W. D. Seider. Heat and power integration of chemical processes. AIChE Journal, 33(6):898-915, June 1987. ISSN 1547-5905. doi: 10.1002/aic.690330604. URL http://onlinelibrary.wiley.com/doi/10.1002/aic.690330604/abstract.

[32] Anna S. Wallerand, Maziar Kermani, Régis Voillat, Ivan Kantor, and François Maréchal. Optimal design of solar-assisted industrial processes considering heat pumping: Case study of a dairy. Renewable Energy, July 2017. ISSN 0960-1481. doi: 10.1016/j.renene.2017.07. 027. URL http://www.sciencedirect.com/science/article/pii/S0960148117306390.

[33] Anna S. Wallerand, Maziar Kermani, Ivan D. Kantor, and François Maréchal. General Superstructure Synthesis and Bi-level Solution Strategy for Industrial Heat Pumping. In Antonio Espuña, Moisès Graells, and Luis Puigjaner, editors, 27th European Symposium on Computer Aided Process Engineering, volume 40 of Computer Aided Chemical Engineering, pages 1159 - 1164. Elsevier, 2017. URL http://www.sciencedirect.com/science/ article/pii/B9780444639653501951. DOI: 10.1016/B978-0-444-63965-3.50195-1.

[34] B. J. Zhang, Z. L. Zhang, K. Liu, and Q. L. Chen. Network Modeling and Design for Low Grade Heat Recovery, Refrigeration, and Utilization in Industrial Parks. Industrial \&3 Engineering Chemistry Research, 55(36):9725-9737, September 2016. ISSN 0888-5885. doi: 10.1021/acs.iecr.6b02033. URL http://dx.doi.org/10.1021/acs.iecr.6b02033.

[35] Gbemi Oluleye, Robin Smith, and Megan Jobson. Modelling and screening heat pump options for the exploitation of low grade waste heat in process sites. Applied Energy, 169:267-286, 2016. ISSN 0306-2619. doi: 10.1016/j.apenergy.2016.02.015. URL http: //www.sciencedirect.com/science/article/pii/S0306261916301386.

[36] Gbemi Oluleye, Megan Jobson, and Robin Smith. Process integration of waste heat upgrading technologies. Process Safety and Environmental Protection, 103, Part B: 
315-333, September 2016. ISSN 0957-5820. doi: 10.1016/j.psep.2016.02.003. URL http://www.sciencedirect.com/science/article/pii/S0957582016000306.

[37] Ha Dinh, Jian Zhang, and Qiang Xu. Process synthesis for cascade refrigeration system based on exergy analysis. AIChE Journal, 61(8):2471-2488, August 2015. ISSN 15475905. doi: 10.1002/aic.14843. URL http://onlinelibrary.wiley.com/doi/10.1002/ aic.14843/abstract.

[38] Guilian Liu, Hua Zhou, Renjie Shen, and Xiao Feng. A graphical method for integrating work exchange network. Applied Energy, 114:588-599, February 2014. ISSN 0306-2619. doi: 10.1016/j.apenergy.2013.10.023. URL http://www.sciencedirect.com/science/ article/pii/S030626191300843X.

[39] Mohd Shariq Khan and Moonyong Lee. Design optimization of single mixed refrigerant natural gas liquefaction process using the particle swarm paradigm with nonlinear constraints. Energy, 49:146-155, January 2013. ISSN 0360-5442. doi: 10.1016/j.energy.2012.11.028. URL http://www.sciencedirect.com/science/article/pii/S0360544212008894.

[40] Roman Hackl and Simon Harvey. Applying exergy and total site analysis for targeting refrigeration shaft power in industrial clusters. Energy, 55:5-14, June 2013. ISSN 0360-5442. doi: 10.1016/j.energy.2013.03.029. URL http://www.sciencedirect.com/ science/article/pii/S036054421300217X.

[41] Helen Becker and François Maréchal. Targeting industrial heat pump integration in multiperiod problems. In Iftekhar A. Karimi and Rajagopalan Srinivasan, editor, Computer Aided Chemical Engineering, volume 31 of 11th International Symposium on Process Systems Engineering, pages 415-419. Elsevier, 2012. URL http://www.sciencedirect.com/ science/article/pii/B9780444595072500755.

[42] Jian Zhang and Qiang Xu. Cascade refrigeration system synthesis based on exergy analysis. Computers \& Chemical Engineering, 35(9):1901-1914, September 2011. ISSN 00981354. doi: 10.1016/j.compchemeng.2011.02.015. URL http://www.sciencedirect.com/ science/article/pii/S0098135411000779.

[43] M. M. Faruque Hasan, Md. Shamsuzzaman Razib, and I. A. Karimi. Optimization of Compressor Networks in LNG Operations. In Caludio Augusto Oller do Nascimento and Evaristo Chalbaud Biscaia Rita Maria de Brito Alves, editor, Computer Aided Chemical Engineering, volume 27 of 10th International Symposium on Process Systems Engineering: Part A, pages 1767-1772. Elsevier, 2009. URL http://www.sciencedirect.com/ science/article/pii/S1570794609706856. DOI: 10.1016/S1570-7946(09)70685-6.

[44] Frank Del Nogal, Jin-Kuk Kim, Simon Perry, and Robin Smith. Optimal Design of Mixed Refrigerant Cycles. Industrial \& Engineering Chemistry Research, 47(22):87248740, November 2008. ISSN 0888-5885. doi: 10.1021/ie800515u. URL http://dx.doi. org/10.1021/ie800515u.

[45] Miguel J. Bagajewicz and Andres F. Barbaro. On the use of heat pumps in total site heat integration. Computers \& Chemical Engineering, 27(11):1707-1719, November 2003. ISSN 0098-1354. doi: 10.1016/S0098-1354(03)00149-2. URL http://www . sciencedirect.com/ science/article/pii/S0098135403001492.

[46] Konstantinos Holiastos and Vasilios Manousiouthakis. Minimum hot/cold/electric utility cost for heat exchange networks. Computers \& Chemical Engineering, 26(1):3-16, 
January 2002. ISSN 0098-1354. doi: 10.1016/S0098-1354(01)00726-8. URL http: //www.sciencedirect.com/science/article/pii/S0098135401007268.

[47] Shankar Vaidyaraman and Costas D. Maranas. Synthesis of Mixed Refrigerant Cascade Cycles. Chemical Engineering Communications, 189(8):1057-1078, August 2002. ISSN 0098-6445. doi: 10.1080/00986440213475. URL http://dx.doi.org/10.1080/ 00986440213475.

[48] F. Maréchal and B. Kalitventzeff. A tool for optimal synthesis of industrial refrigeration systems. In Rafiqul Gani and Sten Bay Jorgensen, editor, Computer Aided Chemical Engineering, volume 9 of European Symposium on Computer Aided Process Engineering - 1134th European Symposium of the Working Party on Computer Aided Process Engineering, pages 457-462. Elsevier, 2001. URL http://www.sciencedirect.com/science/ article/pii/S1570794601800717.

[49] Thomas E Daubert. Physical and thermodynamic properties of pure chemicals: data compilation. Design Institute for Physacal Property Data (DIPPR), 1989.

[50] Friedrich Kauf. Determination of the optimum high pressure for transcritical CO2refrigeration cycles. International Journal of Thermal Sciences, 38(4):325-330, April 1999. ISSN 1290-0729. doi: 10.1016/S1290-0729(99)80098-2. URL http://www. sciencedirect. com/science/article/pii/S1290072999800982.

[51] Erik Wallin and Thore Berntsson. Integration of heat pumps in industrial processes. Heat Recovery Systems and CHP, 14(3):287-296, May 1994. ISSN 0890-4332. doi: 10. 1016/0890-4332(94)90024-8. URL http://www.sciencedirect.com/science/article/ pii/0890433294900248.

[52] B. Linnhoff and V. R. Dhole. Shaftwork targets for low-temperature process design. Chemical Engineering Science, 47(8):2081-2091, June 1992. ISSN 0009-2509. doi: 10. 1016/0009-2509(92)80324-6. URL http://www.sciencedirect.com/science/article/ pii/0009250992803246.

[53] Ross E. Swaney. Thermal integration of processes with heat engines and heat pumps. AIChE Journal, 35(6):1003-1016, June 1989. ISSN 1547-5905. doi: 10.1002/aic.690350614. URL http://onlinelibrary.wiley.com/doi/10.1002/aic.690350614/abstract.

[54] Mark R. Shelton and Ignacio E. Grossmann. A shortcut procedure for refrigeration systems. Computers \& Chemical Engineering, 9(6):615-619, January 1985. ISSN 0098-1354. doi: 10. 1016/0098-1354(85)87017-4. URL http://www.sciencedirect.com/science/article/ pii/0098135485870174.

[55] B. Linnhoff and E. Hindmarsh. The pinch design method for heat exchanger networks. Chemical Engineering Science, 38(5):745-763, January 1983. ISSN 0009-2509. doi: 10. 1016/0009-2509(83)80185-7. URL http://www.sciencedirect.com/science/article/ pii/0009250983801857.

[56] CoolProp. www.coolprop.org, Online; accessed 11-02-2016.

[57] E.W. Lemmon, M.L. Huber, and M.O. McLinden. NIST Standard Reference Database 23: Reference Fluid Thermodynamic and Transport Properties-REFPROP. Standard Reference Data Program Version 9.1, National Institute of Standards and Technology, Gaithersburg, 2013. 
[58] Giorgio Soave. Equilibrium constants from a modified Redlich-Kwong equation of state. Chemical Engineering Science, 27(6):1197-1203, June 1972. ISSN 0009-2509. doi: 10. 1016/0009-2509(72)80096-4. URL http://www.sciencedirect.com/science/article/ pii/0009250972800964.

[59] J. Pongo, W. Boras, R. Schacter, K. Hanson, C. Lowe, and J. Forrest. HYSYS-Reference. Technical Report Vol. 1, 2, Hyprotech Ltd., 1996.

[60] Ding-Yu Peng and Donald B Robinson. A new two-constant equation of state. Industrial Es Engineering Chemistry Fundamentals, 15(1):59-64, 1976.

[61] M.N. Dumont and B. Kalitventzeff. BELSIM Vali H users manual. Technical report, Belsim SA, 1995.

[62] Céline Weber, François Maréchal, and Daniel Favrat. Design and optimization of district energy systems. In Valentin Plesu and Paul Serban Agachi, editor, Computer Aided Chemical Engineering, volume 24 of 17th European Symposium on Computer Aided Process Engineering, pages 1127-1132. Elsevier, 2007. URL http://www.sciencedirect. com/science/article/pii/S1570794607802124.

[63] Min-Jung Yoo, Lindsay Lessard, Maziar Kermani, and Francois Marechal. OsmoseLua An Integrated Approach to Energy Systems Integration with LCIA and GIS. In Kv Gernaey, Jk Huusom, and R Gani, editors, 12Th International Symposium On Process Systems Engineering (Pse) And 25Th European Symposium On Computer Aided Process Engineering (Escape), Pt A, volume 37 of Computer Aided Chemical Engineering, pages 587-592, Amsterdam, 2015. Elsevier Science Bv. ISBN 978-0-444-63578-5.

[64] B.M. Adams, L.E. Bauman, W.J. Bohnhoff, K.R. Dalbey, M.S. Ebeida, J.P. Eddy, M.S. Eldred, P.D. Hough, K.T. Hu, J.D. Jakeman, J.A. Stephens, L.P. Swiler, D.M. Vigil, and T.M. Wildey. Dakota, A Multilevel Parallel Object-Oriented Framework for Design Optimization, Parameter Estimation, Uncertainty Quantification, and Sensitivity Analysis: Version 6.0 User Manual. Technical report, July 2014. URL https://dakota.sandia.gov/ documentation.html.

[65] J.E. Eddy and K. Lewis. Effective generation of pareto sets using genetic programming. In Proceedings of ASME Design Engineering Technical Conference, Pittsburgh, Pennsylvania, 2001.

[66] DW Townsend and B Linnhoff. Surface area targets for heat exchanger networks. In IChemE Annual Research Meeting, Bath, UK, 1984.

[67] Bodo Linnhoff, David R. Mason, and Ian Wardle. Understanding heat exchanger networks. Computers \& Chemical Engineering, 3(1-4):295-302, 1979. ISSN 0098-1354. doi: 10.1016/0098-1354(79)80049-6. URL //www. sciencedirect.com/science/article/pii/ 0098135479800496.

[68] François Maréchal and Boris Kalitventzeff. Targeting the integration of multi-period utility systems for site scale process integration. Applied Thermal Engineering, 23(14): 1763-1784, 2003. ISSN 1359-4311. doi: 10.1016/S1359-4311(03)00142-X. URL http: //www.sciencedirect.com/science/article/pii/S135943110300142X.

[69] Robert Fourer, David M. Gay, and Brian W. Kernighan. AMPL: A Modeling Language for Mathematical Programming. Duxbury Press / Brooks/Cole Publishing Company, 2003. ISBN ISBN 0-534-38809-4. 
[70] IBM ILOG CPLEX Optimization Studio V12.7.0 documentation, February 2015. URL http://www.ibm.com/support/knowledgecenter/SSSA5P_12.7.0/ilog.odms. studio. help/Optimization_Studio/topics/COS_intro_features.html.

[71] AM Lincoff, IE Grossmann, and GE Blau. Separation System for Recovery of Ethylene and Light Products from Naphtha-Pyrolysis Gas Stream. Process Design Case Study, 1985.

[72] Maziar Kermani, Anna S. Wallerand, Ivan D. Kantor, and François Maréchal. Generic superstructure synthesis of organic Rankine cycles for waste heat recovery in industrial processes. Applied Energy, 212:1203-1225, February 2018. ISSN 0306-2619. doi: 10. 1016/j.apenergy.2017.12.094. URL http://www.sciencedirect.com/science/article/ $\mathrm{pii/S0306261917318172.}$

[73] Y. S Chang, M. S Kim, and S. T Ro. Performance and heat transfer characteristics of hydrocarbon refrigerants in a heat pump system. International Journal of Refrigeration, 23(3):232-242, May 2000. ISSN 0140-7007. doi: 10.1016/S0140-7007(99)00042-0. URL http://www.sciencedirect.com/science/article/pii/S0140700799000420.

[74] Huijuan Chen, D. Yogi Goswami, and Elias K. Stefanakos. A review of thermodynamic cycles and working fluids for the conversion of low-grade heat. Renewable and sustainable energy reviews, 14(9):3059-3067, 2010.

[75] T. C. Hung, T. Y. Shai, and S. K. Wang. A review of organic rankine cycles (ORCs) for the recovery of low-grade waste heat. Energy, 22(7):661-667, July 1997. ISSN 0360-5442. doi: 10.1016/S0360-5442(96)00165-X. URL http://www.sciencedirect.com/science/ article/pii/S036054429600165X.

[76] Lon E. Bell. Cooling, heating, generating power, and recovering waste heat with thermoelectric systems. Science, 321(5895):1457-1461, 2008.

[77] Web of Science [v.5.25.1] - Web of Science Core Collection Home, August 2017. URL https ://apps . webofknowledge.com/WOS_GeneralSearch_input.do?product=WOS\& search_mode=GeneralSearch\&SID=R2JaAJG1qMrpvtvJbFY\&preferencesSaved=.

[78] Chao Fu and Truls Gundersen. A Novel Sensible Heat Pump Scheme for Industrial Heat Recovery. Industrial $\&$ Engineering Chemistry Research, 55(4):967-977, February 2016. ISSN 0888-5885. doi: 10.1021/acs.iecr.5b02417. URL http://dx.doi.org/10.1021/acs. iecr.5b02417.

[79] Linde Group. Refrigerants Environmental Data. Ozone Depletion and Global Warming Potential. URL http://www.linde-gas.com/internet.global.lindegas.global/en/ images/Refrigerants\%20environmental\%20GWPs17_111483.pdf.

[80] Jo Gwanggon, Amin Kalantarifard, Jang Jihoon, Byeon Eunsong, Jang Yuna, and Yang Gosu. The effects of malodorous substances from Municipal Solid Waste (MSW) to ClimateChange as Greenhouse-Gas: Calculating GWP of Hydrogen Sulfide. Japan, 2015. URL https://www.jstage.jst.go.jp/article/jsmcwm/26/0/26_547/_pdf.

[81] Kalpesh N. Kothale, Kundlik V. Mali, and S.D. Nimbalkar. Study of R-161 refrigerant as an Alternate Refrigerant to various other refrigerants. In PRESSCO IJCET Special Issue - 4, Pune, India, March 2016. MIT College of Engineering. ISBN E - ISSN 2277 - 4106. URL http://inpressco.com/category/ijcet. 
[82] Nicholas Cox, Victor Mazur, and Daniel Colbourne. New High Pressure Low-G WP Azeotropic and Near-Azeotropic Refrige rant Blends. Purdue, 2008. URL http://docs. lib.purdue.edu/iracc/987.

[83] Aspen Energy Analyzer. Energy Management Software - Energy Optimization |. URL http://aspentech.com/products/engineering/aspen-energy-analyzer/. 


\section{A General}

\section{A.1 Literature review \& heat pump systems}

Analysis of the most cited publications during the past 10 years related to the key word waste heat recovery, demonstrates a dominance of studies dealing with ORC $[74,75]$ and thermoelectric devices [76], while the contributions related to heat pump and refrigeration applications are negligible. Figure 11 illustrates the distribution of the most cited publications within the last 10 years with an average citation of more or equal to five per year. This added up to 158 publications.

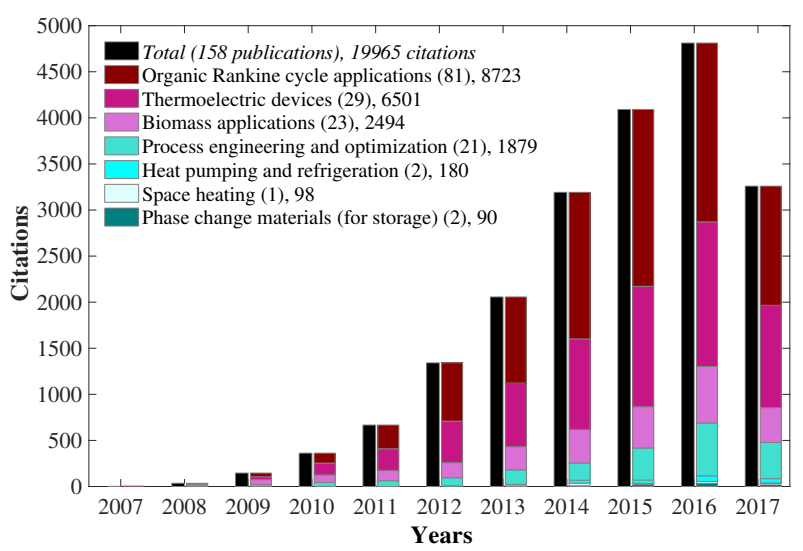

Figure 11: Web of science [77], key words: waste heat recovery, top cited papers of last 10 years ( $\geq 5$ citations/year), accessed 11.08.2017.

Figure 12 shows the temperature enthalpy diagrams of processes (A) and (B). Process (A) has a sharp pinch point with a small temperature lift. While process (B) shows a smooth pinch point with heating and cooling requirements spanning over a range of temperatures. Integration of different mechanical heat pump systems are illustrated, starting from a single-stage, single fluid (inversed Rankine cycle) heat pump in Figure 12-(A) and (B); multi-stage, single fluid heat pumping is shown in Figure 12-(1B); single-stage, multi fluid (zeotropic mixture) is depicted in Figure 12-(2B); and a single-stage, single fluid inverse Brayton heat pump is illustrated in Figure 12-(3B). Single fluid (inverse Rankine) heat pumps can satisfy constant temperature thermal requirements (single-stage) as well as continuous temperature ranges with help of multistage cycles at a reasonable COP. In generating a temperature glide, zeotropic mixtures $[44,47]$ or heat pumps relying on the inverse Brayton cycle [78] may be advantageous for demands spanning wide temperature ranges, but less flexible e.g. with regards to constant temperature requirements. Therefore, this work is focused on the first three figures Figure 12-(A-1B). 

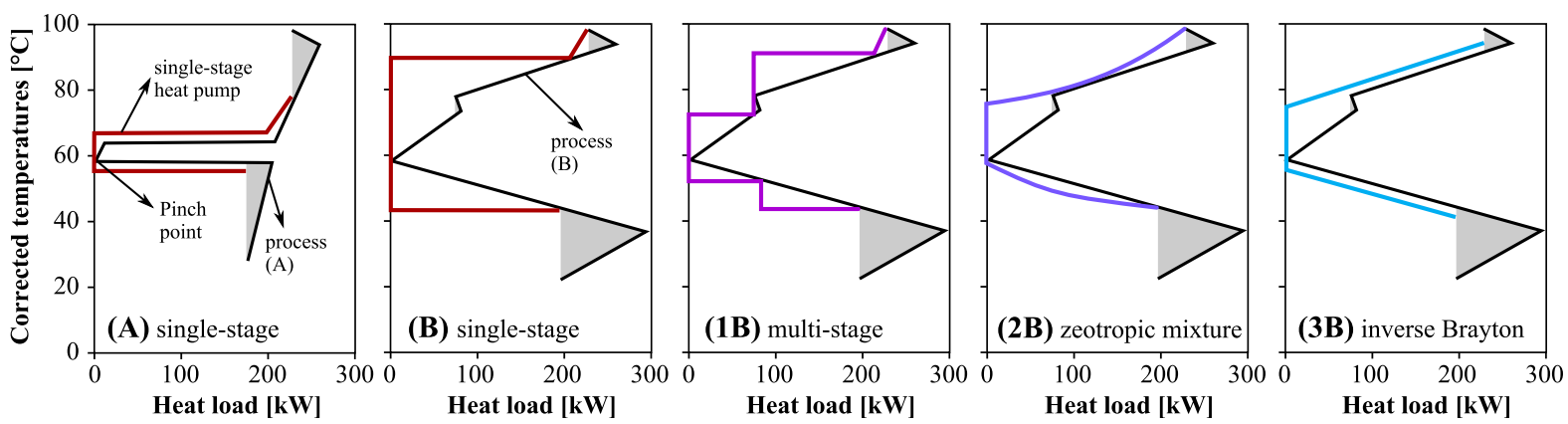

Figure 12: Temperature enthalpy diagram of process (A) and (B) with single-stage heat pump across process pinch point. (1B) multi-stage, single fluid inverse Rankine heat pump, (2B) single-stage, zeotropic fluid mixture inverse Rankine heat pump, (3B) single-stage, single fluid inverse Brayton heat pump.

\section{A.2 MOGA input parameters}

All computations were conducted on a machine with 8-Core Xeon $2.4 \mathrm{GHz}$ processor with 16.0 GB of RAM. Table 7 depicts the data used in the multi-objective genetic algorithm (MOGA [65]) from the Dakota package [64]. Different parameters were used during different runs. Due to danger of getting trapped in local minima, especially during the extended analysis (in section 4.3) with fluid selection at the master level, the mutation and crossover parameters were set more aggressively. These parameters were selected based on a heuristic analysis tracking the propagation of the non-dominated frontier. Figure 13 shows the propagation of MOGA and the dominance of each population over the previous indicating that a total of $10^{5}$ evaluations achieve satisfying convergence.

Table 7: Input parameters for MOGA method [65].

\begin{tabular}{|c|c|c|c|}
\hline Parameter & Expression & Value & Comment \\
\hline Initial population & population_size & 300,500 & initial set of individuals (section $4.2,4.3$ ) \\
\hline Crossover type & crossover_type & $\begin{array}{l}\text { 'shuffle_random' } \\
\text { 'multi_point_binary } 2 \text { ' }\end{array}$ & $\begin{array}{l}\text { (section 4.2) select one of each design var. of the parents for child } \\
\text { (section 4.3) bit switching at } 2 \text { pnts. in the binary encoded genome of two parents }\end{array}$ \\
\hline Mutation type & mutation_type & $\begin{array}{l}\text { 'replace_uniform', } \\
\text { 'bit_random' }\end{array}$ & $\begin{array}{l}\text { (section 4.2) randomly choosing variable and reassigning it to a random valid value } \\
\text { (section 4.3) flips a randomly chosen bit in the string of randomly chosen variable }\end{array}$ \\
\hline Mutation rate & mutation_rate & $0.1,0.2$ & (section $4.2,4.3)$ \\
\hline Percent change & percent_change & $0.1 \quad$ & (default) percent change in non-dominated frontier \\
\hline
\end{tabular}

\section{A.3 MILP input parameters}

The input parameters used for CPLEX [70] are displayed in Table 8. The last three entries were found based on the parameter tuning performed by CPLEX.

Table 8: Input parameters for CPLEX [70], AMPL [69].

\begin{tabular}{llll}
\hline Parameter & Expression & Value & Comment \\
\hline mipgap & 'mipgap' & 0.001 & relative difference between best integer and best bound \\
time & 'time' & 300,600 & cpu time limit in seconds (all, case $S$ ) \\
flow cuts & 'flowcuts' & 1 & (agressive) use of flow cuts in solving MIPs \\
mir cuts & 'mircuts' & 1 & (moderate) generation of MIP rounding cuts \\
branch & 'branch' & 1 & branching direction for integer variables \\
\hline
\end{tabular}




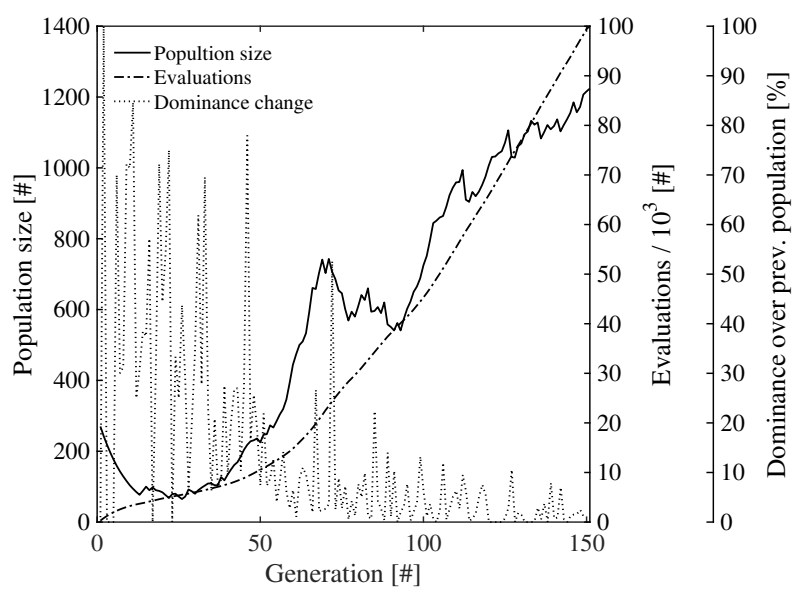

Figure 13: Analysis of MOGA propagation including non-dominated frontier in $10^{5}$ evaluations of extended case E2, master level fluid selection.

\section{B Input data}

\section{B.1 Benchmark cases}

The thermal streams considered in the different benchmark cases are depicted in the original source and were reproduced in Table 9. The objective functions, variables, boundary conditions, and input data to the respective optimization problems are displayed in Table 10. The HEN costs were disregarded during this optimization following the literature input data.

In case E2, gas-cooling was considered. It has to be noted that the temperature difference below which gas-cooling was realised was not selected as a variable. It was set to the difference between the temperature level $i$ and the one above $(i-1)$, yielding $\Delta T_{i, D S H}=T_{i-1}-T_{i}$. The main effect of this choice is ensuring that the generated solutions do not require splitting of the gas-cooling thermal streams, in other words, they do not require several heat exchangers cooling gas at one compressor outlet.

Table 9: Streams data of the three benchmark cases.

(a) E2 [23]

\begin{tabular}{lllll}
\hline Stream name & $\begin{array}{l}\mathrm{T}_{\text {in }} \\
\mathrm{K}\end{array}$ & $\begin{array}{l}\mathrm{T}_{\text {out }} \\
\mathrm{K}\end{array}$ & $\begin{array}{l}\Delta \mathrm{Q} \\
\mathrm{kW} / \mathrm{K}\end{array}$ & $\begin{array}{l}\alpha \\
\mathrm{kW} / \mathrm{m}^{2} \mathrm{~K}\end{array}$ \\
\hline Process & & & & \\
\hline $\mathrm{H} 1$ & 360 & 320 & 10 & 1 \\
$\mathrm{H} 2$ & 320 & 250 & 10 & 1 \\
$\mathrm{C} 1$ & 260 & 310 & 15 & 1 \\
$\mathrm{C} 2$ & 300 & 360 & 10 & 1
\end{tabular}

\begin{tabular}{llll}
\hline Utilities & $\mathrm{K}$ & $\mathrm{K}$ & \\
\hline Water for cooling & 300 & 310 & 0.56 \\
Water for heating $^{*}$ & 300 & 290 & 0.56 \\
Steam & 440 & 440 & 0.56
\end{tabular}

(b) Ethylene [25]

\begin{tabular}{|c|c|c|c|c|}
\hline Stream name & $\begin{array}{l}\mathrm{T}_{\text {in }} \\
\mathrm{K}\end{array}$ & $\begin{array}{l}\mathrm{T}_{\text {out }} \\
\mathrm{K}\end{array}$ & $\begin{array}{l}\Delta \mathrm{Q} \\
\mathrm{kW}\end{array}$ & $\begin{array}{l}\alpha \\
\mathrm{kW} / \mathrm{m}^{2} \mathrm{~K}\end{array}$ \\
\hline \multicolumn{5}{|l|}{ Process } \\
\hline H1 & 408 & 312 & -1186 & 1 \\
\hline $\mathrm{H} 2$ & 375 & 312 & -466 & 1 \\
\hline H3 & 375 & 312 & -387 & 1 \\
\hline $\mathrm{H} 4$ & 375 & 312 & -380 & 1 \\
\hline H5 & 375 & 290 & -572 & 1 \\
\hline $\mathrm{H} 6$ & 269 & 260 & -20 & 1 \\
\hline $\mathrm{H} 7$ & 168 & 158 & -157 & 1 \\
\hline $\mathrm{H} 8$ & 258 & 256.8 & -381 & 1 \\
\hline H9 & 313 & 313 & -224 & 1 \\
\hline H10 & 307 & 307 & -141 & 1 \\
\hline H11 & 234 & 234 & -1081 & 1 \\
\hline H12 & 290 & 230 & -451 & 1 \\
\hline $\mathrm{C} 1$ & 393 & 440 & 111 & 1 \\
\hline $\mathrm{C} 2$ & 277 & 302 & 174 & 1 \\
\hline C3 & 158 & 311 & 208 & 1 \\
\hline $\mathrm{C} 4$ & 346 & 360 & 516 & 1 \\
\hline $\mathrm{C} 5$ & 436 & 498 & 448 & 1 \\
\hline $\mathrm{C} 6$ & 315 & 358 & 133 & 1 \\
\hline $\mathrm{C} 7$ & 252 & 256 & 1120 & 1 \\
\hline $\mathrm{C} 8$ & 247 & 298 & 96 & 1 \\
\hline Utilities & $\mathrm{K}$ & $\mathrm{K}$ & & \\
\hline Cooling water for cooling & 297.1 & 300 & & 0.56 \\
\hline Cooling water for heating* & 297.1 & 294.2 & & 0.56 \\
\hline Steam LP & 411 & 411 & & 1 \\
\hline
\end{tabular}

(c) Cold Tray [31]

\begin{tabular}{lllll}
\hline Stream name & $\begin{array}{l}\mathrm{T}_{\text {in }} \\
\mathrm{K}\end{array}$ & $\begin{array}{l}\mathrm{T}_{\text {out }} \\
\mathrm{K}\end{array}$ & $\begin{array}{l}\Delta \mathrm{Q} \\
\mathrm{kW}\end{array}$ & $\begin{array}{l}\alpha \\
\mathrm{kW} / \mathrm{m}^{2} \mathrm{~K}\end{array}$ \\
\hline Process & & & & \\
\hline $\mathrm{H} 1$ & -10.7 & -10.7 & -400.70 & 1 \\
$\mathrm{H} 2$ & -28.9 & -28.9 & -823.38 & 1 \\
$\mathrm{H} 3$ & 51.5 & 51.5 & -4285.30 & 1 \\
C1 & 67.9 & 67.9 & 870.83 & 1 \\
C2 & -3 & -3 & 758.94 & 1 \\
C3 & 62.5 & 62.5 & 4229.65 & 1
\end{tabular}

\begin{tabular}{llll}
\hline Utilities & $\mathrm{K}$ & $\mathrm{K}$ & \\
\hline Cooling water for cooling & 295 & 300 & 0.56 \\
Cooling water for heating* & 295 & 290 & 0.56 \\
Steam & 138 & 13882 & 1
\end{tabular}


Table 10: Benchmark cases data.

\begin{tabular}{|c|c|c|c|c|c|c|c|c|c|c|c|c|c|}
\hline \multirow[t]{2}{*}{ Description } & \multirow[t]{2}{*}{ Symbols } & \multicolumn{4}{|c|}{ E2 } & \multicolumn{4}{|c|}{ Ethylene } & \multicolumn{4}{|c|}{ Cold Tray } \\
\hline & & Data & $\begin{array}{l}\text { Unit } \\
\end{array}$ & Reference & $\min (\mathrm{HPS})$ & Data & Unit & Reference & $\min (\mathrm{HPS})$ & Data & Unit & Reference & $\min (\mathrm{HPS})$ \\
\hline \multicolumn{14}{|l|}{ Master level } \\
\hline 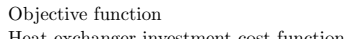 & 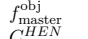 & $\left\{C^{O P E X}, C^{C A P E X}\right\}$ & $\$ / y$ & \multirow{2}{*}{\multicolumn{10}{|c|}{ Table 6}} \\
\hline $\begin{array}{l}\text { Heat exchanger investment cost function } \\
\text { Heat exchanger investment cost function }\end{array}$ & $C^{C O M P}$ & $\begin{array}{l}0 \\
\text { as slave }\end{array}$ & $\begin{array}{l}\$ / y \\
\$ / y\end{array}$ & & & & & & & & & & \\
\hline \multicolumn{4}{|c|}{ Variables } & \multicolumn{10}{|c|}{ Table 6} \\
\hline Saturation temperature & $\begin{array}{l}T_{1} \\
T_{2} \\
T_{3} \\
T_{4} \\
T_{5} \\
T_{6} \\
T_{7} \\
T_{8} \\
T_{9} \\
T_{10}\end{array}$ & $\begin{array}{l}\{300,300.5, \ldots, 313\} \\
\{290,290.5, \ldots, 310\} \\
\{280,2005.5, \ldots, 300\} \\
\{265,265.5, \ldots, 285\} \\
\{250,2505.5, \ldots, 270\} \\
2425,245.5, \ldots, 265\}\end{array}$ & $\begin{array}{l}\mathrm{K} \\
\mathrm{K} \\
\mathrm{K} \\
\mathrm{K} \\
\mathrm{K} \\
\mathrm{K} \\
\mathrm{K} \\
\mathrm{K}\end{array}$ & $\begin{array}{l}313 \\
300 \\
288 \\
277 \\
254 \\
247 \\
240\end{array}$ & $\begin{array}{l}312.5 \\
288.5 \\
283 \\
272 \\
254 \\
248 \\
240\end{array}$ & $\begin{array}{l}\{310,310.5, \ldots, 310\} \\
\{250,250.5, \ldots, 20\} \\
\{230,230.5, \ldots, 280\} \\
\{220,220.5, \ldots, 260\} \\
\{200,200.5, \ldots, 240\} \\
\{190,190.5, \ldots, 20\} \\
\{170,170.5, \ldots, 210\} \\
\{160,160.5, \ldots, 20\} \\
\{150,110.5, \ldots, 190\} \\
148\end{array}$ & $\begin{array}{l}\mathrm{K} \\
\mathrm{K} \\
\mathrm{K} \\
\mathrm{K} \\
\mathrm{K} \\
\mathrm{K} \\
\mathrm{K} \\
\mathrm{K} \\
\mathrm{K} \\
\mathrm{K} \\
\mathrm{K} \\
\mathrm{K} \\
\mathrm{K}\end{array}$ & $\begin{array}{l}310 \text {, ammonia } \\
307 \text {, } 22 \\
297, \text { ammonia } \\
266, \text { r22 } \\
256, \text { r22 } \\
\text { 256.8, propylene } \\
\text { 246.8, r22 } \\
\text { 234, ethane } \\
\text { 224, propylene } \\
\text { ethane }\end{array}$ & $\begin{array}{l}310 \text {, ammonia } \\
26.5, \text { ammonia } \\
246 \text {, ammonia } \\
234, \text { ethane } \\
224, \text { ammonia } \\
205, \text { ethane } \\
189 \text {, ethane } \\
180.5 \text {, ethane } \\
172 \text {, thane } \\
\text { ethane }\end{array}$ & 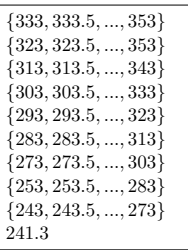 & $\begin{array}{l}\mathrm{K} \\
\mathrm{K} \\
\mathrm{K} \\
\mathrm{K} \\
\mathrm{K} \\
\mathrm{K} \\
\mathrm{K} \\
\mathrm{K} \\
\mathrm{K} \\
\mathrm{K} \\
\mathrm{K} \\
\mathrm{K} \\
\mathrm{K}\end{array}$ & $\begin{array}{l}- \\
- \\
303, \text { r22,ammonia } \\
274, \text { r22 } \\
259.5, \text { ammonia } \\
\text { r22 }\end{array}$ & $\begin{array}{l}344 \\
338.5 \\
331 \\
321.5 \\
302 \\
298 \\
273 \\
259.5 \\
257\end{array}$ \\
\hline Subcooling temperature difference & $\begin{array}{l}\Delta T_{i, S C} \\
\Delta T_{1, S C} \\
\Delta T_{2, S C} \\
\Delta T_{3, S C} \\
\Delta T_{4, S C} \\
\Delta T_{5, S C} \\
\Delta T_{6, S C}\end{array}$ & $\begin{array}{l}\{0,1, \ldots, 20\} \\
\{0,1, \ldots, 20\} \\
\{0,1, \ldots, 15\} \\
\{0,1, \ldots, 15\} \\
\{0,1, \ldots, 5\} \\
\{0,1, \ldots, 5\}\end{array}$ & $\begin{array}{l}\mathrm{K} \\
\mathrm{K} \\
\mathrm{K} \\
\mathrm{K} \\
\mathrm{K} \\
\mathrm{K} \\
\mathrm{K}\end{array}$ & $\begin{array}{l}0 \\
0 \\
0 \\
0 \\
0 \\
0 \\
0\end{array}$ & $\begin{array}{l}14 \\
15 \\
0 \\
2 \\
0 \\
0 \\
\end{array}$ & 0 & $\mathrm{~K}$ & & & 0 & $\mathrm{~K}$ & & \\
\hline $\begin{array}{l}\text { Gas-cooling temperature difference } \\
\text { Preheatitin temperature difference } \\
\text { Fluid set }\end{array}$ & $\begin{array}{l}\Delta T_{i, D S H} \\
\Delta T_{i, P R E}\end{array}$ & $\begin{array}{l}T_{i-1}-T_{i} \\
0 \\
\text { \{ammonia\} }\end{array}$ & $\begin{array}{l}\mathrm{K} \\
\mathrm{K}\end{array}$ & $\begin{array}{l}0 \\
0 \\
\text { ammonia }\end{array}$ & $\begin{array}{l}\text { as shown } \\
0 \\
\text { ammonia }\end{array}$ & $\mid \begin{array}{l}0 \\
0 \\
\text { \{ammonia, propylene, r22, } \\
\text { r13, ethane, ethylene }\}\end{array}$ & $\begin{array}{l}\mathrm{K} \\
\mathrm{K}\end{array}$ & & & $\begin{array}{l}0 \\
0 \\
\text { \{ammonia, r12, r22\} }\end{array}$ & $\begin{array}{l}\mathrm{K} \\
\mathrm{K}\end{array}$ & & ammonia \\
\hline Weighting factor & $\xi$ & {$[0,1]$} & - & 0.5 & 0.47 & {$[0,1]$} & - & 0.5 & 0.87 & {$[0,1]$} & - & 0.5 & 0.74 \\
\hline \multicolumn{14}{|l|}{ Slave level } \\
\hline Objective function & $f_{\text {slave }}^{\text {obj }}$ & $w T A C$ & $\$ / \mathrm{y}$ & & & $w T A C$ & $\$ / \mathrm{y}$ & & & $w T A C$ & $\$ / y$ & & \\
\hline Parameters taken from $[23]$ & & & & & & Parameters taken from [25] & & & & Parameters taken fror & $\mathrm{n}[31]$ & & \\
\hline $\begin{array}{l}\text { Compressor isentropic efficiency } \\
\text { Minimum temperature difference } \\
\text { Set of periods } \\
\text { Operating time of period } \\
\text { Occurence of period } \\
\text { Maximum compression ratio } \\
\text { Maximum number of compressors }\end{array}$ & $\begin{array}{l}r_{\text {isentropic }} \\
\Delta \mathrm{T}_{\min } \\
\mathrm{P}^{-\mathrm{t}_{1}} \\
\text { occ1 } \\
\mathrm{CP}^{\max } \\
\mathrm{n}^{\max }\end{array}$ & $\begin{array}{l}1 \\
10 \\
\{1\} \\
1 \\
1\end{array}$ & $\begin{array}{l}\mathrm{y} \\
1 / \mathrm{y}\end{array}$ & & & $\begin{array}{l}1 \\
10 \\
\{1\} \\
1 \\
1 \\
10 \\
5 \\
\end{array}$ & $\begin{array}{l} \\
\mathrm{K} \\
- \\
\mathrm{y} \\
1 / \mathrm{y} \\
\mathrm{bar} / \mathrm{bar}\end{array}$ & & & $\begin{array}{l}1 \\
2.78 \\
\{1\} \\
1 \\
1\end{array}$ & $\begin{array}{l} \\
K \\
- \\
y \\
1 / y\end{array}$ & & \\
\hline \multicolumn{14}{|l|}{ Opex } \\
\hline Steam production & $\mathrm{OP}_{2}^{\text {steam }}$ & 50.91 & $\$ / \mathrm{kW} / \mathrm{y}$ & & & 0 & $\$ / \mathrm{kW} / \mathrm{y}$ & & & 56.2866 & $\$ / \mathrm{kW} / \mathrm{y}$ & & \\
\hline Electricity grid & $\mathrm{OP}_{2}^{\text {grid }}$ & 608.33 & $\$ / \mathrm{kW} / \mathrm{y}$ & & & 336 & $\$ / \mathrm{kW} / \mathrm{y}$ & & & 420 & $\$ / \mathrm{kW} / \mathrm{y}$ & & \\
\hline Cooling water & $\mathrm{OP}_{2}^{2 \mathrm{w}}$ & 15.97 & $\$ / \mathrm{kW} / \mathrm{y}$ & & & 6.011 & $\$ / \mathrm{kW} / \mathrm{y}$ & & & 6.011 & $\$ / \mathrm{kW} / \mathrm{y}$ & & \\
\hline \multicolumn{14}{|l|}{ Capex } \\
\hline $\begin{array}{l}\text { Compressor cost } \\
\text { Heat exchanger cost parameters }\end{array}$ & $\begin{array}{l}\mathrm{IV} \mathrm{V}^{\text {comp }} \\
\mathrm{IV} \mathrm{V}_{\mathrm{b}}^{\text {comp }} \\
\mathrm{a}, \mathrm{b} \\
\mathrm{U} \\
\mathrm{A} \\
\mathrm{Q}^{\min }\end{array}$ & $\begin{array}{l}2824.8 \\
831.67 \\
50,0.8 \\
1 \\
1 \\
7\end{array}$ & $\begin{array}{l}\$ / \mathrm{y} \\
\$ / \mathrm{kW} / \mathrm{y} \\
\$,- \\
\mathrm{kW} / \mathrm{m}^{2} \mathrm{~K} \\
\mathrm{~m}^{2} \\
\mathrm{~kW}\end{array}$ & & & $\begin{array}{l}0.15 \cdot 3,787.4 \\
0.15 \cdot 1,573 \\
500,0.8 \\
1 \\
1 \\
100\end{array}$ & $\begin{array}{l}\$ / \mathrm{y} \\
\$ / \mathrm{kW} / \mathrm{y} \\
\$,- \\
\mathrm{kW} / \mathrm{m}^{2} \mathrm{~K} \\
\mathrm{~m}^{2} \\
\mathrm{~kW}\end{array}$ & & & $\begin{array}{l}0.15 \cdot 3,787.4 \\
0.15 \cdot 1,573 \\
500,0.8 \\
1 \\
1 \\
7\end{array}$ & $\begin{array}{l}\$ / \mathrm{y} \\
\$ / \mathrm{kW} / \mathrm{y} \\
\$,- \\
\mathrm{kW} / \mathrm{m}^{2} \mathrm{~K} \\
\mathrm{~m}^{2} \\
\mathrm{~kW}\end{array}$ & & \\
\hline
\end{tabular}




\section{B.2 Extended case $E 2$}

The thermal streams considered in this case are depicted in Table 9(a). Figure 14a shows the parallel coordinates information generated with the tool from Kermani et al. [72]. The GWP of most selected Hydrofluorocarbonss (HFCs) (r407c, r404a, r410a, r507a) is above 1500 [79] compared to hydrogen sulfide and natural refrigerants (ammonia (r717), propane (r290), propylene (r1270)) with GWP of below 10 [79, 80] and lower-impact HFCs such as r161 (12 [81]) and $\mathrm{r} 41$ (97 [82]). The objective functions, variables, boundary conditions, and input data to the extended case E2 are displayed in Table 11. Figure 14b depicts the temperature entropy diagram of the optimized HPS solution. Figure 15a displays the integrated composite curves of the extended case. In the reference case, cooling water is required to cool the highest condenser level which is increased compared to the benchmark case due to the lower compressor isentropic efficiency. Since the cooling water outlet temperature is above the condenser temperature, part of it needs to be heated by the hot utility. Figure $15 \mathrm{~b}$ presents a flowsheet of the minimum TAC case. The two HEN design of the reference and optimized case is shown in Figure 16. It has to be noted that the HPS solution requires one more heat exchangers which is mildly penalized by the HEN cost function thereby being outweighed by the benefits of the reduced opex.

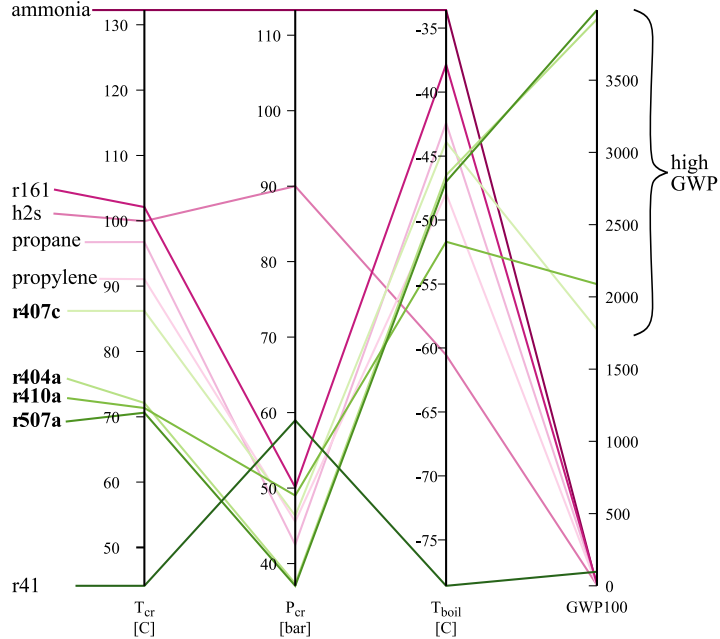

(a) Relevant data of selected fluids. Parallel coordinates selection platform [72] (thermodynamic properties: CoolProp [56] GWP data: [79-82]).

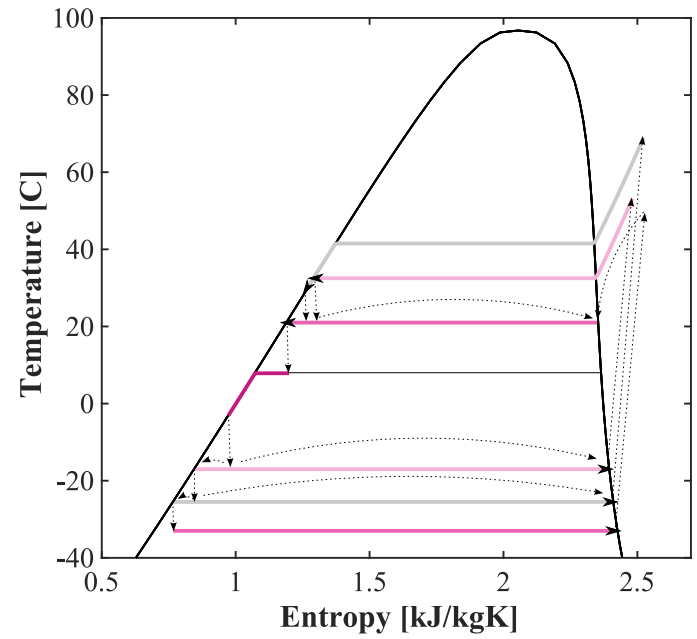

(b) Temperature entropy diagram of the minimum TAC solution.

Figure 14: Set of selected fluids considered during multi-objective optimization. 


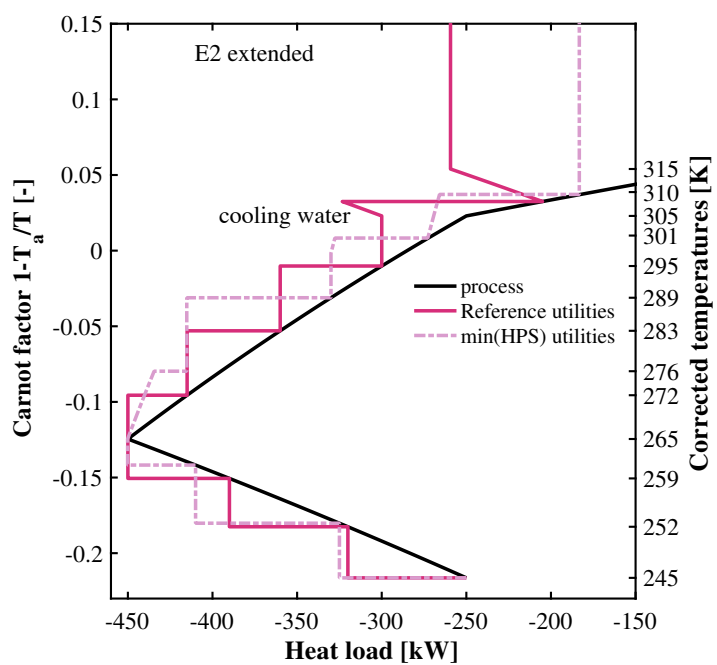

(a) Integrated composite curves of optimized and reference case.

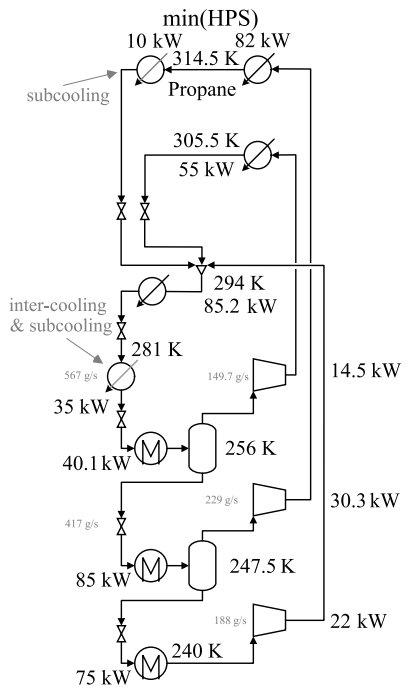

(b) Flowsheet of optimum case.

Figure 15: Extended case E2 minimum TAC solution.

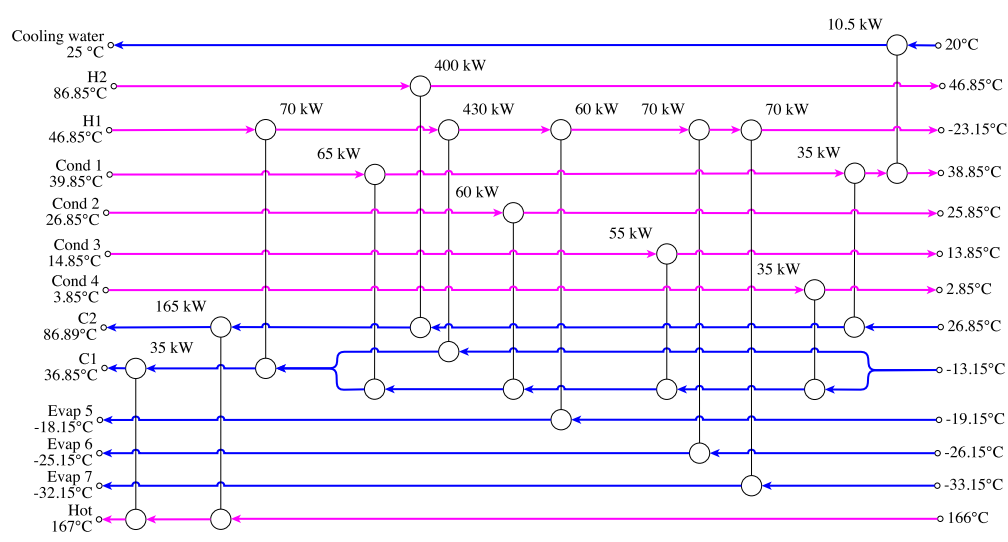

(a) HEN design of extended reference case E2.

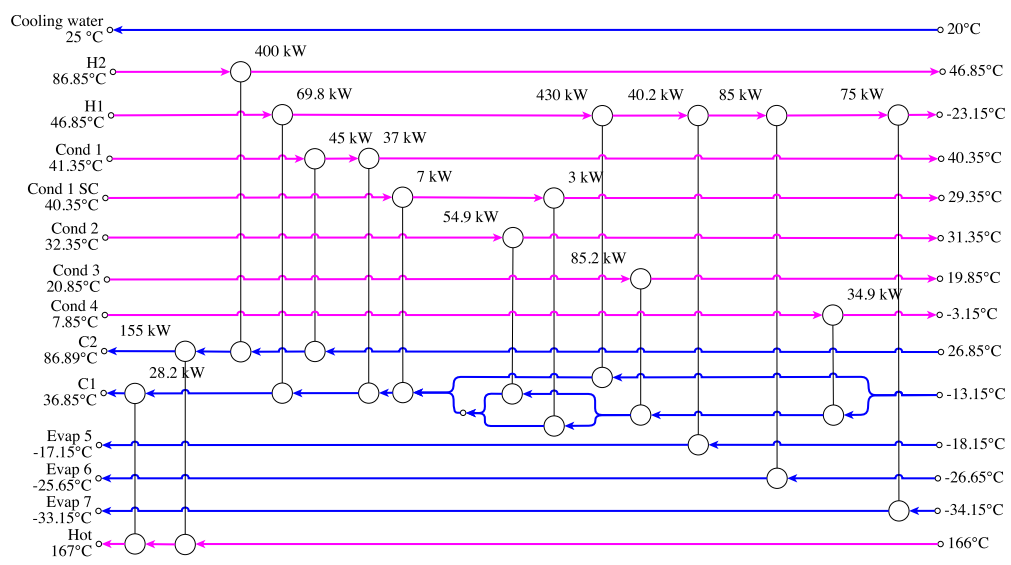

(b) HEN design of extended case E2 minimum TAC solution.

Figure 16: HEN design with Aspen Energy Analyzer [83]. 
Table 11: Optimization problem description: extended case E2.

\begin{tabular}{|c|c|c|c|c|c|}
\hline Description & Symbols & Data & Unit & Reference & $\min (\mathrm{HPS})$ \\
\hline \multicolumn{6}{|l|}{ Master level } \\
\hline Objective function & $f_{\text {master }}^{\text {obj }}$ & $\left\{C^{O P E X}, C^{C A P E X}\right\}$ & $\$ / y$ & $\begin{array}{l}56005 \\
132608\end{array}$ & $\begin{array}{l}49944 \\
121840\end{array}$ \\
\hline $\begin{array}{l}\text { Heat exchanger cost function (estimation) } \\
\text { HEN design }\end{array}$ & $C^{H E N}$ & $C^{H E N}$ Table 3 & $\begin{array}{l}\$ / y \\
\$ / y\end{array}$ & $\begin{array}{l}58800 \\
52800\end{array}$ & $\begin{array}{l}57800 \\
53600\end{array}$ \\
\hline \multirow{3}{*}{ HEN design } & $c_{1}$ fitted from $[23]$ & 0 & $\$$ & & \\
\hline & $c_{2}$ fitted from $[23]$ & 500 & $\$ / y$ & & \\
\hline & $\mathrm{c}_{3}$ fitted from $[23]$ & 0.8 & - & & \\
\hline \multicolumn{6}{|l|}{ Variables } \\
\hline \multirow[t]{8}{*}{ Saturation temperature } & $\mathrm{T}_{i}=\mathrm{T}_{i+1}+\Delta T_{i}$ & & & & \\
\hline & $\Delta T_{1}$ & $\{5,5.5, \ldots, 40\}$ & $\mathrm{K}$ & 13 & 9 \\
\hline & $\Delta T_{2}$ & $\{5,5.5, \ldots, 40\}$ & $\mathrm{K}$ & 12 & 11.5 \\
\hline & $\Delta T_{3}$ & $\{5,5.5, \ldots, 40\}$ & $\mathrm{K}$ & 11 & 13 \\
\hline & $\Delta T_{4}$ & $\{5,5.5, \ldots, 40\}$ & $\mathrm{K}$ & 23 & 25 \\
\hline & $\Delta T_{5}$ & $\{5,5.5, \ldots, 40\}$ & $\mathrm{K}$ & 7 & 8.5 \\
\hline & $\Delta T_{6}$ & $\{5,5.5, \ldots, 40\}$ & $\mathrm{K}$ & 7 & 7.5 \\
\hline \multirow{2}{*}{\multicolumn{6}{|c|}{ Subcooling temperature difference }} \\
\hline & & & & & \\
\hline & $\Delta T_{1, S C}$ & $\{0,1, \ldots, 20\}$ & $\mathrm{K}$ & 0 & 12 \\
\hline & $\Delta T_{2, S C}$ & $\{0,1, \ldots, 20\}$ & $\mathrm{K}$ & 0 & 0 \\
\hline & $\Delta T_{3, S C}$ & $\{0,1, \ldots, 15\}$ & $\mathrm{K}$ & 0 & 0 \\
\hline & $\Delta T_{4, S C}$ & $\{0,1, \ldots, 15\}$ & $\mathrm{K}$ & 0 & 11 \\
\hline & $\Delta T_{5, S C}$ & $\{0,1, \ldots, 10\}$ & $\mathrm{K}$ & 0 & 0 \\
\hline & $\Delta T_{6, S C}$ & $\{0,1, \ldots, 10\}$ & $\mathrm{K}$ & 0 & \\
\hline De-superheating temperature difference & $\Delta T_{i, D S H}$ & $T_{i-1}-T_{i}$ & $\mathrm{~K}$ & 0 & as indicated \\
\hline Preheating temperature difference & $\triangle T_{i, P R E}$ & 0 & $\mathrm{~K}$ & & \\
\hline Fluid set & $\mathbf{F}$ & $\begin{array}{l}\text { \{ammonia,r161,h2s,propane,propylene, } \\
\mathrm{r} 407 \mathrm{c}, \mathrm{r} 404 \mathrm{a}, \mathrm{r} 410 \mathrm{a}, \mathrm{r} 507 \mathrm{a}, \mathrm{r} 41\}\end{array}$ & & ammonia & propane \\
\hline Weighting factor & $\xi$ & {$[0,1]$} & - & 0.5 & 0.58 \\
\hline \multicolumn{6}{|l|}{ Slave level } \\
\hline Objective function & $\begin{array}{l}f_{\text {slave }}^{\mathrm{obj}} \\
\end{array}$ & $w T A C$ & $\$ / y$ & & \\
\hline \multicolumn{6}{|l|}{ Parameters } \\
\hline Compressor isentropic efficiency & $\eta_{\text {isentropic }}$ & 0.7 & - & & \\
\hline Minimum temperature difference & $\Delta \mathrm{T}_{\min }$ & 10 & $\mathrm{~K}$ & & \\
\hline Set of periods & $\mathbf{P}$ & $\{1\}$ & - & & \\
\hline Operating time of period & $\Delta \mathrm{t}_{1}$ & 1 & y & & \\
\hline Occurence of period & $\mathrm{occ}_{1}$ & 1 & $1 / \mathrm{y}$ & & \\
\hline Maximum compression ratio & $\mathrm{CP}^{\max }$ & 8 & $\mathrm{bar} / \mathrm{bar}$ & & \\
\hline \multicolumn{6}{|l|}{ Opex } \\
\hline Steam production & $\mathrm{OP}_{2}^{\text {steam }}$ & 50.91 & $\$ / \mathrm{kW} / \mathrm{y}$ & & \\
\hline Electricity grid & $\mathrm{OP}_{2}^{\text {grid }}$ & 608.33 & $\$ / \mathrm{kW} / \mathrm{y}$ & & \\
\hline Cooling water & $\mathrm{OP}_{2}^{\mathrm{cw}}$ & 15.97 & $\$ / \mathrm{kW} / \mathrm{y}$ & & \\
\hline \multicolumn{6}{|l|}{ Capex } \\
\hline Compressor cost & $\begin{array}{l}\mathrm{IV}_{\text {comp }}^{\text {comp }} \\
\mathrm{IV} V_{2}^{\text {comp }}\end{array}$ & $\begin{array}{l}2824.8 \\
831.67\end{array}$ & $\begin{array}{l}\$ / \mathrm{y} \\
\$ / \mathrm{kW} / \mathrm{y}\end{array}$ & & \\
\hline
\end{tabular}




\section{Slave level - mathematical fomulation}

\section{C.1 Utility targeting constraints}

The general utility targeting problem is derived based on the work by Maréchal and Kalitventzeff [68].

Heat cascade The second law of thermodynamics states that heat can only flow from a source at higher temperature to a sink at colder temperature and is expressed in the heat cascade constraints in Equation 13-14. These constraints ensure maximum heat recovery in the system.

$$
\begin{gathered}
\sum_{w \in \mathbf{W}} f_{p}^{w} \cdot \dot{\mathrm{Q}}_{p, k}^{w}+\sum_{s \in \mathbf{S}} \dot{\mathrm{Q}}_{p, k}^{s}+\dot{R}_{p, k+1}-\dot{R}_{p, k}=0 \quad \forall p \in \mathbf{P}, k \in \mathbf{K} \\
\dot{R}_{p, k} \geq 0, \quad \dot{R}_{p, 1}=0, \quad \dot{R}_{p, \mathrm{n}_{\mathrm{k}}+1}=0 \quad \forall p \in \mathbf{P}, k \in \mathbf{K}
\end{gathered}
$$

Where

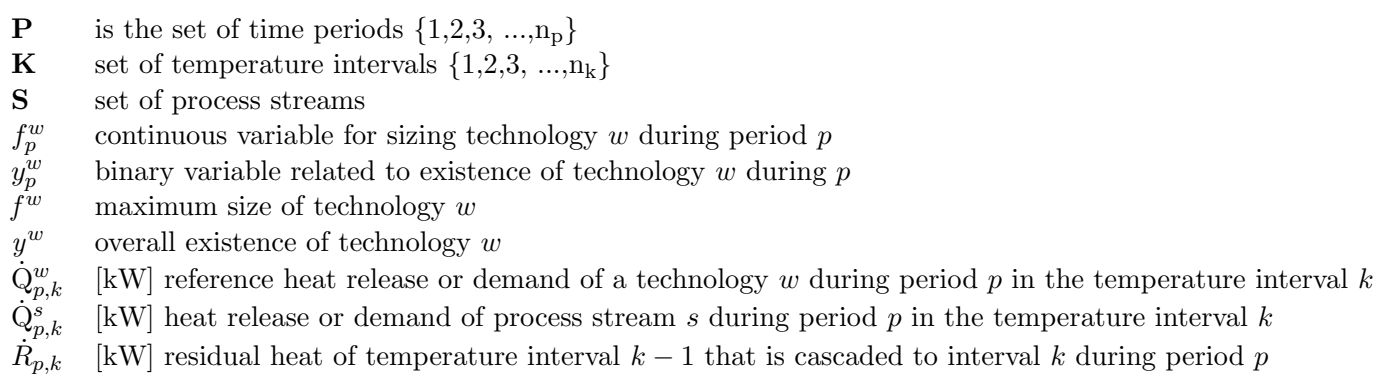

Sizing constraints The dimensions of the utility technologies are constrained between specified boundaries as depicted in Equation 15.

$$
f^{w}-f_{p}^{w} \geq 0, \quad y^{w}-y_{p}^{w} \geq 0, \quad \mathrm{f}^{w, \min } \cdot y_{p}^{w} \leq f_{p}^{w} \leq \mathrm{f}^{w, \max } \cdot y_{p}^{w} \quad \forall p \in \mathbf{P}
$$

Electricity balance The electricity balance in Equation 16 is closed by considering the electricity input and output of all utility technologies $w$.

$$
\sum_{w \in \mathbf{W}} f_{p}^{w} \cdot \dot{\mathrm{E}}^{w}=0 \quad \forall p \in \mathbf{P}
$$

Where

$\dot{\mathrm{E}}^{w} \quad[\mathrm{~kW}]$ reference electricity consumption (positive) or production (negative) of a technology $w$ during period $p$

Natural gas balance The natural gas balance in Equation 17 is closed by considering the natural gas input and output of all utility technologies $w$.

$$
\sum_{w \in \mathbf{W}} f_{p}^{w} \cdot \dot{\mathrm{Q}}^{w}=0 \quad \forall p \in \mathbf{P}
$$

Where

$\dot{\mathrm{Q}}^{w} \quad[\mathrm{~kW}]$ reference natural gas input (positive) or output (negative) of a technology $w$ during period $p$ 


\section{C.2 Heat pump superstructure}

\section{C.2.1 HPS parameters entering the utility targeting}

In the following formulations, the heat and electricity consumption or production of the heat pump utilities is described for a reference mass flow rate which is to say, a fixed size. These parameters enter into the utility targeting constraints Equation 13-15 where they are multiplied with sizing factors.

The heat release in a condenser at saturation temperature $\mathrm{T}_{i}$ of heat pump $g$ for a reference flow rate $\dot{\mathrm{m}}_{\mathrm{ref}}[\mathrm{kg} / \mathrm{s}]$ is composed of three parts: de-superheating from the preheating level $\mathrm{T}_{i, \mathrm{PRE}}[\mathrm{K}]$, condensation at the saturation temperature, and subcooling between saturation and subcooling temperature $\mathrm{T}_{i, \mathrm{SC}}[\mathrm{K}]$. As such, the heat release in a condenser is defined by Equation 18.

$$
\begin{aligned}
\dot{\mathrm{Q}}^{g, \text { cond, } i} & =-\dot{\mathrm{m}}_{\mathrm{ref}} \cdot\left(\left[\mathrm{h}_{\mathrm{PRE}}\left(\mathrm{T}_{i}\right)-\mathrm{h}_{\mathrm{V}}\left(\mathrm{T}_{i}\right)\right]_{\mathrm{T}_{i}}^{\mathrm{T}_{i, \mathrm{PRE}}}+\left[\mathrm{h}_{\mathrm{V}}\left(\mathrm{T}_{i}\right)-\mathrm{h}_{\mathrm{L}}\left(\mathrm{T}_{i}\right)\right]_{\mathrm{T}_{i}}+\left[\mathrm{h}_{\mathrm{L}}\left(\mathrm{T}_{i}\right)-\mathrm{h}_{\mathrm{SC}}\left(\mathrm{T}_{i}\right)\right]_{\mathrm{T}_{i, \mathrm{SC}}}^{\mathrm{T}_{i}}\right) \\
& =-\dot{\mathrm{m}}_{\mathrm{ref}} \cdot\left(\Delta \mathrm{h}_{\mathrm{cond}}\left(\mathrm{T}_{i}\right)+\Delta \mathrm{h}_{\mathrm{SC}}\left(\mathrm{T}_{i}\right)+\Delta \mathrm{h}_{\mathrm{PRE}}\left(\mathrm{T}_{i}\right)\right)
\end{aligned}
$$

Where $T_{i, P R E}$ is the preheating temperature before compression $[K], h_{P R E}$ is the enthalpy before compression $[\mathrm{kJ} / \mathrm{kg}], \mathrm{h}_{\mathrm{V}}[\mathrm{kJ} / \mathrm{kg}]$ is the vapor and $\mathrm{h}_{\mathrm{L}}[\mathrm{kJ} / \mathrm{kg}]$ is the liquid saturation enthalpy.

The heat consumption of an evaporator at saturation temperature $T_{i}$ of heat pump $g$ is composed of two parts: evaporation at the saturation temperature and superheating between saturation and preheating temperature. As such, the heat consumption in an evaporator is defined by Equation 19 .

$$
\begin{aligned}
\dot{\mathrm{Q}}^{g, \text { evap }, i} & =\dot{\mathrm{m}}_{\text {ref }} \cdot\left(\left[\mathrm{h}_{\mathrm{V}}\left(\mathrm{T}_{i}\right)-\mathrm{h}_{\mathrm{L}}\left(\mathrm{T}_{i}\right)\right]_{\mathrm{T}_{i}}+\left[\mathrm{h}_{\mathrm{PRE}}\left(\mathrm{T}_{i}\right)-\mathrm{h}_{\mathrm{V}}\left(\mathrm{T}_{i}\right)\right]_{\mathrm{T}_{i}}^{\mathrm{T}_{i, \mathrm{PRE}}}\right) \\
& =\dot{\mathrm{m}}_{\mathrm{ref}} \cdot\left(\Delta \mathrm{h}_{\text {evap }}\left(\mathrm{T}_{i}\right)+\Delta \mathrm{h}_{\mathrm{PRE}}\left(\mathrm{T}_{i}\right)\right)
\end{aligned}
$$

The liquid side of the presaturator also needs to be cooled down to the subcooling temperature which is formulated similarly and shown by Equation 20 .

$$
\dot{\mathrm{Q}}^{g, \text { presat, } i}=\dot{\mathrm{m}}_{\mathrm{ref}} \cdot\left[\mathrm{h}_{\mathrm{L}}\left(\mathrm{T}_{i}\right)-\mathrm{h}_{\mathrm{SC}}\left(\mathrm{T}_{i}\right)\right]_{\mathrm{T} i, \mathrm{SC}}^{\mathrm{T}_{i}}
$$

Gas-cooling to the compressor inlet temperature from the superheated vapor at the compressor outlet can be achieved by mixing in the presaturator or in a heat exchanger as described in Equation 21.

$$
\dot{\mathrm{Q}}^{g \text {, gas-cool, } i}=\dot{\mathrm{m}}_{\mathrm{ref}} \cdot\left[\mathrm{h}_{\mathrm{SH}}\left(\mathrm{T}_{i}\right)-\mathrm{h}_{\mathrm{PRE}}\left(\mathrm{T}_{i}\right)\right]_{\mathrm{T}_{i, \mathrm{PRE}}}^{\mathrm{T} i \mathrm{SH}}
$$

Where $\mathrm{h}_{\mathrm{SH}}$ is the enthalpy to which the superheated compressor outlets are mixed $[\mathrm{kJ} / \mathrm{kg}]$, and $\mathrm{T}_{i, \mathrm{SH}}$ is the respective temperature $[\mathrm{K}]$.

The electricity consumption of a compressor depends on the isentropic efficiency and the enthalpies of both pressure levels, formulated as Equation 22.

$$
\dot{\mathrm{E}}^{g, \text { comp }, i \rightarrow j}=\dot{\mathrm{m}}_{\text {ref }} \cdot\left[\frac{\mathrm{h}_{\text {isentropic }}\left(\mathrm{T}_{j}\right)-\mathrm{h}_{\mathrm{V}}\left(\mathrm{T}_{i}\right)}{\eta_{\text {isentropic }}}\right]
$$

Where $\mathrm{h}_{\text {isentropic }}\left(\mathrm{T}_{j}\right)[\mathrm{kJ} / \mathrm{kg}]$ is the isentropic enthalpy after compression from saturated vapor at temperature level $\mathrm{T}_{i}$ to (saturation) temperature level $\mathrm{T}_{j}$, and $\eta_{\text {isentropic }}$ is the isentropic compressor efficiency [-]. The HPS stream properties are depicted in Table 12. 
Table 12: Data of streams of the HPS.

\begin{tabular}{llllll}
\hline Unit & Name & $\mathrm{T}_{\mathrm{in}}$ & $\mathrm{T}_{\text {out }}$ & $|\Delta \mathrm{Q}|$ & $\alpha$ \\
& & $\mathrm{K}$ & $\mathrm{K}$ & $\mathrm{kJ} / \mathrm{kg}$ & $\mathrm{kW} / \mathrm{m}^{2} \mathrm{~K}$ \\
\hline \multirow{2}{*}{ Condenser } & condensation & $\mathrm{T}_{i}$ & $\mathrm{~T}_{i}$ & $\mathrm{~h}_{\mathrm{V}}\left(\mathrm{T}_{i}\right)-\mathrm{h}_{\mathrm{L}}\left(\mathrm{T}_{i}\right)$ & 1.6 \\
& sub-cooling & $\mathrm{T}_{i}$ & $\mathrm{~T}_{i, \mathrm{SC}}$ & $\mathrm{h}_{\mathrm{L}}\left(\mathrm{T}_{i}\right)-\mathrm{h}_{\mathrm{SC}}\left(\mathrm{T}_{i}\right)$ & 0.56 \\
& de-superheating & $\mathrm{T}_{i, \mathrm{PRE}}$ & $\mathrm{T}_{i}$ & $\mathrm{~h}_{\mathrm{PRE}}\left(\mathrm{T}_{i}\right)-\mathrm{h}_{\mathrm{V}}\left(\mathrm{T}_{i}\right)$ & 0.06 \\
\multirow{3}{*}{ Evaporator } & evaporation & $\mathrm{T}_{i}$ & $\mathrm{~T}_{i}$ & $\mathrm{~h}_{\mathrm{V}}\left(\mathrm{T}_{i}\right)-\mathrm{h}_{\mathrm{L}}\left(\mathrm{T}_{i}\right)$ & 3.6 \\
& preheating & $\mathrm{T}_{i}$ & $\mathrm{~T}_{i, \mathrm{PRE}}$ & $\Delta \mathrm{h}_{\mathrm{PRE}}\left(\mathrm{T}_{i}\right)$ & 0.06 \\
Gas-cooler & gas-cooling & $\mathrm{T}_{i, \mathrm{SH}}$ & $\mathrm{T}_{i, \mathrm{PRE}}$ & $\mathrm{h}_{\mathrm{SH}}\left(\mathrm{T}_{i}\right)-\mathrm{h}_{\mathrm{PRE}}\left(\mathrm{T}_{i}\right)$ & 0.06 \\
Presaturator & sub-cooling & $\mathrm{T}_{i}$ & $\mathrm{~T}_{i, \mathrm{SC}}$ & $\mathrm{h}_{\mathrm{L}}\left(\mathrm{T}_{i}\right)-\mathrm{h}_{\mathrm{SC}}\left(\mathrm{T}_{i}\right)$ & 0.56 \\
\hline
\end{tabular}

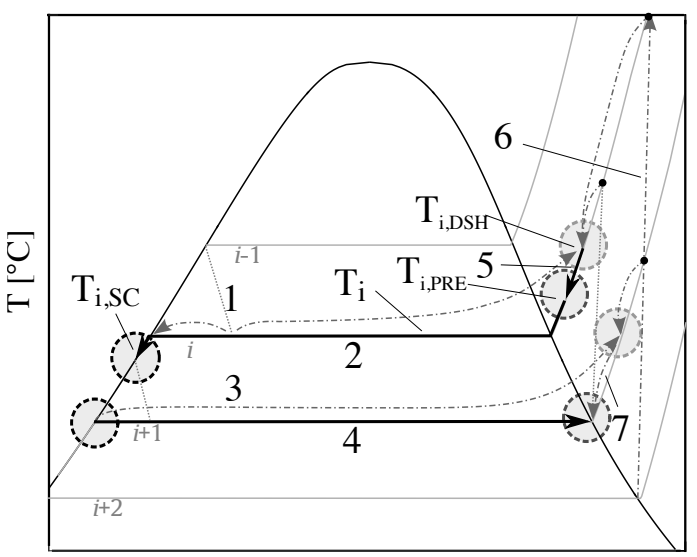

Legend

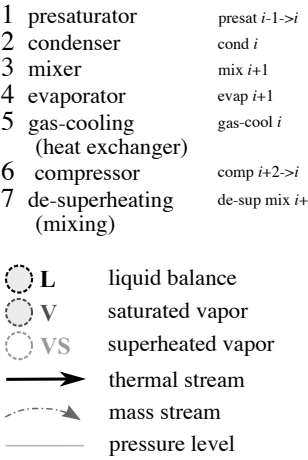

Entropy $[\mathrm{kJ} / \mathrm{kgK}]$

Figure 17: Temperature-entropy diagram with mass and energy balances of the HPS.

\section{C.2.2 Heat pump specific constraints}

In the following the heat pump specific linear equations at the slave level are introduced.

Liquid mass balance The liquid mass balance at temperature level $i$ can be at saturated or sub-cooled conditions depending whether $\Delta \mathrm{T}_{i}, \mathrm{SC}>0$ (sub-cooled) or $\Delta \mathrm{T}_{i, \mathrm{SC}}=0$ (saturated). It is shown in Equation 23 of heat pump $g$ and is composed of:

- the positive contribution from the potential condenser at level $i$

- the negative contribution from the potential evaporator at level $i$

- the positive contribution of the liquid fraction of all valves in combination with presaturators that end at level $i$

- the negative contribution from all valves that exit from level $i$

- the negative contribution of the fraction of liquid that may be used to de-superheat the compressor outlets (mix) at level $i$

$$
\begin{aligned}
& f_{p}^{g, \text { cond } i}-f_{p}^{g, \text { evap } i}+\sum_{j=1}^{i-1}\left(1-\mathrm{x}_{\mathrm{V}}^{g j \rightarrow i}\right) \cdot f_{p}^{g, \text { presat } j \rightarrow i}-\sum_{k=i+1}^{\mathrm{n}_{1}} f_{p}^{g, \text { presat } i \rightarrow k}-f_{p}^{g, \text { mix } i}=0 \\
& \forall i \in \mathbf{L}, g \in \mathbf{G}, p \in \mathbf{P}
\end{aligned}
$$

Where

$\mathbf{G}$
$\mathbf{L}$
$f_{p}^{g, \operatorname{cond} i}$
$f_{p}^{g, \text { evap } i}$
$f_{p}^{g, \operatorname{mix} i}$
$f_{p}^{g, \text { presat } j \rightarrow i}$
$\mathrm{x}_{\mathrm{V}}^{g j \rightarrow i}$
$\mathrm{~h}_{\mathrm{SC}}^{g i}$ set of heat pumps $g$ consisting of one fluid $d$

set of heat pump saturation temperature levels $\left\{1,2,3, \ldots, \mathrm{n}_{1}\right\}$

condenser sizing factor of heat pump $g$ (containing fluid f) during period $p$

evaporator sizing factor of heat pump $g$ during period $p$

mixer sizing factor of heat pump $g$ during period $p$

presaturator after expansion from temperature level $j \rightarrow i$ sizing factor of heat pump $g$ during period $p$

vapor fraction after expansion from temperature level $j \rightarrow i$ of heat pump $g$

$[\mathrm{kJ} / \mathrm{kg}]$ enthalpy at subcooled or saturated temperature level $\mathrm{T}_{i, \mathrm{SC}}=\mathrm{T}_{i}-\Delta \mathrm{T}_{i}$, SC of heat pump $g$ 
Liquid energy balance The liquid energy balance in Equation 24 is trivial because all streams enter and exit at the same state of matter and temperature.

$$
\begin{aligned}
& \left(f_{p}^{g, \text { cond } i}-f_{p}^{g, \text { evap } i}+\sum_{j=1}^{i-1}\left(1-\mathrm{x}_{\mathrm{V}}^{g j \rightarrow i}\right) \cdot f_{p}^{g, \text { presat } j \rightarrow i}-\sum_{k=i+1}^{\mathrm{n}_{1}} f_{p}^{g, \text { presat } i \rightarrow k}-f_{p}^{g, \text { mix } i}\right) \cdot \mathrm{h}_{\mathrm{SC}}^{g i}=0 \\
& \forall i \in \mathbf{L}, g \in \mathbf{G}, p \in \mathbf{P}
\end{aligned}
$$

Vapor mass balance The vapor mass balance at temperature level $i$ can be at saturated or superheated conditions depending whether $\Delta \mathrm{T}_{i, \text { PRE }}>0$ (superheated) or $\Delta \mathrm{T}_{i}$, PRE $=0$ (saturated). It is shown in Equation 25 of heat pump $g$ and is composed of:

- the positive contribution from the potential evaporator at level $i$

- the negative contribution from the potential condenser at level $i$

- the negative contribution from all compressors that exit from level $i$

- the potential incoming mass flow related to the potential gas-cooling heat exchanger unit from the superheated mass balance at level $i$

- the potential positive contribution from a de-superheating through mixing unit at level $i$

$$
\begin{aligned}
& f_{p}^{g, \text { evap } i}-f_{p}^{g, \text { cond } i}-\sum_{j=1}^{i-1} f_{p}^{g, \text { comp } i \rightarrow j}+f_{p}^{g, \text { gas-cool } i}+f_{p}^{g, \text { de-sup mix } i}=0 \\
& \forall i \in \mathbf{L}, g \in \mathbf{G}, p \in \mathbf{P}
\end{aligned}
$$

Where

$$
\begin{array}{ll}
f_{p}^{g, \text { comp } j \rightarrow i} & \text { sizing factor of compressor from level } j \rightarrow i \text { sizing factor of heat pump } g \text { during period } p \\
f_{p}^{g} \text {, de-sup mix } i & \text { sizing factor of the de-superheating through mixing unit of heat pump } g \text { during period } p \\
f_{p}^{g} \text {, gas-cool } i & \text { sizing factor of the gas-cooling heat exchanger of heat pump } g \text { during period } p
\end{array}
$$

The energy balance in this case is trivial, since all streams enter and exist at $\mathrm{h}_{\mathrm{PRE}}^{g i}[\mathrm{~kJ} / \mathrm{kg}]$, the enthalpy at preheated or saturated temperature level $\mathrm{T}_{i}$, PRE $=\mathrm{T}_{i}+\Delta \mathrm{T}_{i}$, PRE of heat pump $g$. This balance is not displayed here.

Superheated vapor mass balance The superheated vapor mass balance at temperature level $i$ is conducted at superheated conditions $\Delta \mathrm{T}_{i, \mathrm{SH}}=\mathrm{T}_{i}+\Delta \mathrm{T}_{i}$, SH. It is shown in Equation 26 of heat pump $g$ and is composed of:

- the positive contributions of each compressor entering level $i$

- the positive contribution of the vapor fraction of all valves in combination with presaturators that end at level $i$

- the negative contribution from the gas-cooling and de-superheating through mixing units at level $i$

- and the positive contribution from the liquid mixing unit at level $i$

$$
\begin{aligned}
& \sum_{k=i+1}^{\mathrm{n}_{1}} f_{p}^{g, \text { comp } k \rightarrow i}+\sum_{j=1}^{i-1} \mathrm{x}_{\mathrm{V}}^{g{ }^{j \rightarrow i}} \cdot f_{p}^{g, \text { presat } j \rightarrow i}-f_{p}^{g, \text { gas-cool } i}-f_{p}^{g, \text { de-sup mix } i}+f_{p}^{g, \text { mix } i}=0 \\
& \quad \forall i \in \mathbf{L}, g \in \mathbf{G}, p \in \mathbf{P}
\end{aligned}
$$

Superheated vapor energy balance The energy balance given in Equation 27 ensures that regardless of which compressor is active, the starting point for de-superheating is always fixed. This constraint ensures energy conservation and linearity in the problem formulation.

$$
\begin{aligned}
& \sum_{k=i+1}^{\mathrm{n}_{1}} f_{p}^{g, \text { comp } k \rightarrow i} \cdot \mathrm{h}_{\text {out }}^{g, \text { comp } k \rightarrow i}-f_{p}^{g, \text { gas-cool } i} \cdot \mathrm{h}_{\mathrm{SH}}^{g i}-f_{p}^{g, \text { de-sup mix } i} \cdot \mathrm{h}_{\mathrm{PRE}}^{g i}+f_{p}^{g, \text { mix } i} \cdot \mathrm{h}_{\mathrm{L}}^{g i}=0 \\
& \quad \forall i \in \mathbf{L}, g \in \mathbf{G}, p \in \mathbf{P}
\end{aligned}
$$

Where 
$\mathrm{h}_{\mathrm{PRE}}^{g i} \quad[\mathrm{~kJ} / \mathrm{kg}]$ enthalpy at preheated or saturated temperature level $\mathrm{T}_{i, \text { PRE }}=\mathrm{T}_{i}+\Delta \mathrm{T}_{i, \text { PRE }}$ of heat pump $g$ $\mathrm{h}_{\mathrm{SH}}^{g i} \quad[\mathrm{~kJ} / \mathrm{kg}]$ superheated vapor enthalpy at point $\mathrm{T}_{i, \mathrm{SH}}=\mathrm{T}_{i}+\Delta \mathrm{T}_{i, \mathrm{SH}}$

$\mathrm{h}_{\text {out }}^{\text {g,comp } k \rightarrow i} \quad[\mathrm{~kJ} / \mathrm{kg}]$ outlet enthalpy of compressor from level $k$ to $i$ 